\title{
Automatic Grade Promotion and Student Performance: Evidence from Brazil
}

\author{
Martin Foureaux Koppensteiner \\ Department of Economics \\ University of Leicester \\ University Road \\ Leicester \\ LE1 7HR. \\ UK \\ Email: mfkoppensteiner@le.ac.uk \\ Telephone: +44 1162522467 \\ Fax: +44 1162522908
}

\begin{abstract}
This paper examines the effect of automatic grade promotion on academic achievement in 1,993 public primary schools in Brazil. A difference-in-differences approach that exploits variation over time and across schools in the grade promotion regime allows the identification of the treatment effect of automatic promotion. I find a negative and significant effect of about $7 \%$ of a standard deviation on math test scores. I provide evidence in support of the interpretation of the estimates as disincentive effect of automatic promotion. The findings contribute to the understanding of retention policies by focussing on the ex-ante effect of repetition and are important for more complete costbenefit considerations of grade retention.
\end{abstract}

Keywords: Grade retention, automatic promotion, incentives to learn, primary education, Brazil.

JEL numbers: I28, I21, O15, H52 


\section{INTRODUCTION}

Grade retention, the practice of holding back students in the same grade for an extra year if they fail to achieve promotion requirements - either in the form of a performance measure or in the form of minimum attendance - is used in many developing and in some developed countries. It is particularly widespread and pronounced in African and Latin American countries, where repetition rates are often as high as $30 \%$ (UNESCO 2008). ${ }^{1}$ Historically grade repetition had a prominent role in Brazil and repetition rates in Brazilian primary schools reached $24 \%$ in first grade and $14 \%$ in fourth grade in $2005 .^{2}$

Retaining students has important consequences both for the individual as well as for schools. Overall, every repeater has the same effect on school resources as enrolling an additional student at that grade and subsequent grades and either leads to compromising per pupil school inputs e.g. through larger class size or to a pressure on public finances through the additional demand for teachers, classrooms, desks and other inputs. ${ }^{3}$

Opponents of grade repetition contend that it negatively impacts the retained individual by stigmatizing them and harming their self-esteem, by impairing established peer relationships and generally alienating the individual from school, which may in turn negatively affect academic achievement and increase the probability of dropping-out of school (Holmes 1989). Furthermore, repeating grades delays entrance of students into the labour market which poses substantial monetary cost on individuals over the life-cycle. In contrast, proponents argue that repetition can improve academic achievement by exposing low performing students to additional teaching and by allowing them to catch up on the curriculum and the content of teaching. This is particularly important if school absence for reasons such as illness in a given school year is the reason for retention. Grade retention may also

\footnotetext{
${ }^{1} 40$ out of 43 African countries for which data is available in 2006 use grade retention (and for which average repetition rates exceed $4 \%$ in primary school) and 18 out of 23 Latin American and Caribbean countries.

2 Data available at http://stats.uis.unesco.org/unesco/ReportFolders/ReportFolders.aspx. UNESCO Institute for Statistics, Data Centre, January 2012.

${ }^{3}$ A very rough estimate of the annual cost of repetition on public finances in Brazil using average expenditure per pupil at primary schools in 2006 of \$554 (in constant 2005 US\$) and 18,661,000 students enrolled at primary school and an average repetition rate over all grades of $18.7 \%$ (not accounting for loss of students due to drop-out etc.) amounts to approximately 1.9 billion US\$ (all data from UNESCO 2008).
} 
help to make classes more homogeneous in achievement and therefore easier to teach by improving the match between peers in the classroom (Manacorda 2012).

There is a small but growing literature on estimating the causal effect of retention on subsequent educational outcomes (Gomes-Neto and Hanushek 1994, Eide and Showalter 2001, Dong 2009, Jacob and Lefgren 2004 and 2009, Manacorda 2012 and Glick and Sahn 2010). The results are mixed, with positive as well as negative estimates of the effect of repetition on academic achievement and school drop-out, and the results seem to depend critically on context and age of students.

Considering these mixed empirical findings on the effect on repeaters, the use of public resources and the undesirable consequences for public finances, the persistence of grade retention regimes in many countries is puzzling. This is particularly the case for developing countries where repetition rates are often very high and pressure on public resources is large. Furthermore, repetition increases the age variation in the classroom and repeaters may also directly lead to negative externalities on their peer students (Manski 1993, Lavy, Paserman and Schlosser 2012).

A possible explanation for the persistence of grade retention in many countries may be based on the deterrence effect of grade retention. ${ }^{4}$ Grade retention induces students to exert effort as it potentially inflicts substantial costs of repetition on low performers. The ex-ante threat of retention may therefore incentivize students to study in order to avoid being retained. This incentive effect of grade retention may have an important effect on mean student outcomes, as it is not restricted to repeaters only, but may create incentives for a much wider range of students. While the empirical literature on grade retention focuses on the ex-post effect on repeaters, there exists to the author's knowledge - no research on the ex-ante effect of the promotion regime on academic outcomes of a wider set of students. This analysis examines the effect of removing the deterrence of retention rather than estimating the effect of repetition on repeaters. Automatic grade promotion has been introduced in Brazil on a large scale since the early 2000's partly to accelerate progress towards meeting the Millennium Development Goal of universal primary education and to reducing the cost of larger student cohorts (UNESCO 2012). I exploit credible exogenous variation in the timing

\footnotetext{
${ }^{4}$ Manacorda (2012) is the first to point out such a deterrence effect of retention in the literature. A related argument of a deterrence effect is discussed by Angrist et al. (2002) in relation to school vouchers and by Jacob (2005) in relation to high stakes testing in the US.
} 
of the adoption of automatic promotion for identification in a difference-indifferences (DiD) setting.

I find that the introduction of automatic promotion significantly reduces academic achievement measured by math test scores of fourth graders by $6.7 \%$ of a standard deviation. Quantile DiD results show that the strongest treatment effect can be found for the lower part of the test score distribution with considerably smaller effects in the tails of the distribution. This is consistent with an interpretation of the estimates as a disincentive effect of automatic promotion and the paper provides additional evidence in support of this interpretation. There is no evidence that the results are caused by teacher or school responses to the introduction of automatic promotion. Teachers are no more or less likely to assign and correct their students' homework, and class size is unaffected by the policy introduction. Because there is only limited information on teaching practices available it is not possible to rule out completely the possibility of unobserved systematic teacher responses to the policy. The timing of the policy change limits the potential for changes in the student composition of the test cohorts and I provide strong evidence that the socio-economic composition is unaffected by the policy and unlikely biases the estimates. There is also no evidence that the estimates are affected by systematic changes in student mobility across schools or by strategic test taking behaviour.

The remainder of the paper is organized as follows. Section 2 provides information on the school system in Brazil and in the state of Minas Gerais. Section 3 presents the data. Section 4 describes the natural experiment and outlines the assignment of schools to treatment. Section 5 introduces the empirical strategy. The results, their interpretation and falsification exercises are presented in section 6, and section 7 concludes.

\section{THE SCHOOL SYSTEM IN BRAZIL AND MINAS GERAIS}

Primary school is compulsory in Brazil for children between the ages of 7 to 14 and consists of eight years of schooling (MEC 1996). ${ }^{5}$ Public schooling is free at all ages and enrolment in primary and secondary school is open to students of all ages.

The Brazilian educational system has undergone substantial changes during the last two decades and has achieved considerable progress in expanding access to

\footnotetext{
${ }^{5}$ The school entry age has recently been lowered to 6 years and primary school has been extended to 9 years.
} 
education. Starting from a primary school net enrolment rate of $85 \%$ in 1991, Brazil achieves today almost universal primary school enrolment with a net rate of $95 \%$ (UNESCO 2008). Primary school completion and youth literacy rates have improved notably, but the country continues to suffer from high repetition and drop-out rates. ${ }^{6}$

The national conditional cash transfer programme Bolsa Família, formerly Bolsa Escola, which is a means-tested monthly cash transfer to poor households conditional on school enrolment and regular attendance among other conditions, plays a significant role for the rise in school enrolment and attendance of school age children (de Janvry, Finan and Sadoulet 2006). ${ }^{7}$

This analysis focuses on the state of Minas Gerais, the second most populous state in Brazil with an estimated population of about 19 million (IBGE 2007). Minas Gerais contributes $10 \%$ to the Brazilian GDP and is among the most developed states in Brazil (OECD 2005). The education system of Minas Gerais is among the most advanced and in national performance tests students regularly perform among the top (INEP 2007).

According to state legislation, the State Secretariat of Education (SEE) has extensive authority to plan, direct, execute, control and evaluate all educational activities in Minas Gerais. Based on the far-reaching decentralization of education in Brazil, the SEE transfers authority to a large extent to Regional Authorities for Education (Superintendências Regionais de Ensino: SREs) and directly to the municipalities. SREs and municipalities therefore play a major role in the provision of schooling and the implementation of educational policies. ${ }^{8}$ Municipal schools account for more than half $(56 \%)$ of all primary schools and state schools, that are directly under the control of the SEE, account for $22 \%$ of all schools. Besides the public provision of education private schools play an important role and account for the remaining $22 \%{ }^{9}$

\footnotetext{
${ }^{6}$ The overall repetition rate in primary schools in Brazil in 2006 was $18.7 \%$ and the total drop-out rate for primary school 19.5\% (UNESCO 2008).

${ }^{7}$ The conditionalities of Bolsa Família require a minimum school attendance of $85 \%$ and extend to the fulfilment of basic health care requirements such as vaccinations of the children and pre and postnatal medical consultations for pregnant women. Monthly per capita income in the household cannot exceed $\mathrm{R} \$ 120$ (US\$57 in 2006) to remain eligible for the transfer. See Lindert et al. 2007 for a comprehensive description of the programme.

${ }^{8}$ The installation of FUNDEF, a federal fund established in 1996 with the aim of redistributing state and municipal resources back to (mainly) municipalities according to student numbers contributed to the improvement of the control of municipalities over educational decisions. See de Mello \& Hoppe (2005) for an analysis of FUNDEF.

9 There are also 28 federal schools in Brazil which are under the direct control of the federal government; the single federal school in Minas Gerais has not been included in the dataset.
} 


\section{DATA DESCRIPTION}

This study uses data from two sources. Information on school characteristics comes from the annual Brazilian school census that is conducted by the National Institute for the Study and Research on Education (INEP) under the control of the Federal Ministry of Education (MEC). The Brazilian school census compiles data annually from all primary and secondary schools in Brazil. The exceptionally rich data includes information on the location and administrative dependence of schools, physical characteristics (quantity of premises and class rooms, equipment and teaching material), the participation in national, state and municipal school programmes, the number of teachers and administrative staff, average class-size, detailed information on student flows (number of students in each grade by age, repetition, drop-out and student transfer rates) among other information. Summary statistics for the public schools used in this analysis are presented in panel A of table A1 in the annex.

The school census also contains the information on the grade promotion regime adopted in each school (grade retention versus automatic promotion), which is used to establish treatment and control groups.

The second part of the data comes from the State System of the Evaluation of Public Education (Sistema Mineiro de Avaliação da Educação Pública: SIMAVE), which includes the programme for the evaluation of state primary and secondary schools (Programa de Avaliação da Educação Básica: PROEB). ${ }^{10}$ Results from the programme are used for the evaluation and design of educational policies in the state; the results are, however, not used by the schools to evaluate individual student performance, for example for the grade promotion decision.

The main outcome variable is student achievement in state schools in Minas Gerais measured by math test scores in 2003 and 2006. All classes and all students in fourth grade of each school are examined and participation of schools and students is compulsory. The cognitive test scores are standardized to a mean of 500 and a standard deviation of 100 . In total 246,959 students have been tested in 1,993 state schools in Minas Gerais. I use the repeated cross-section of test score data from 2003 and 2006 for this analysis. The students in the dataset have, as generally students in public schools, a deprived socioeconomic background. Almost half (45.6\%) of the

\footnotetext{
${ }^{10}$ Schools under the administration of the municipality or the federal government are not included in SIMAVE.
} 
families with children at state schools in Minas Gerais qualify for Bolsa Família and can be considered poor. Information on sex, date of birth, racial background and on the socio-economic family background is also available from an adjunct questionnaire. Unfortunately, only the 2003 wave of the socio-economic questionnaire contains information on parental education. Chart B of table A1 presents summary statistics on these variables.

\section{THE GENERAL EDUCATION ACT OF 1996: THE CASE OF A QUASI- EXPERIMENT}

\subsection{Policy background}

The General Education Act of 1996 (Lei de Diretrizes e Bases da Educação Nacional: LDB) paved the way for the introduction of automatic promotion policies in Brazil. Federal Law No 9.394/1996, which came into effect in 1998, regulates the responsibility for education between the federal, state and municipal level and facilitated federal and state programmes to control the grade promotion regime (Pino and Koslinski 1999). Section 3 of Art. $32 \S 1 \& 2$ formally distinguishes two alternatives for educational authorities to organize student progression: besides the conventional annual grade promotion regime the option of automatic promotion was introduced, a system in which students progress automatically to the next grade at the end of the school year. Between these two extremes, a mixture of both regimes was also permitted. In the mixed regime, schools define "learning cycles" that stretch over several - most commonly three - school years. During the initial years of the cycle students are promoted automatically. In the final year of a cycle students that fail to meet the minimum requirements set in the curriculum are retained. The idea behind learning cycles is to allow students an individual studying pace (Mainardes 2010). If students fall behind their classmates they have a longer period to catch up on the curriculum. This particularly aims at reducing the long-run impact of negative temporary shocks, such as school days lost to sickness or adverse family events. For mixed regime schools that have adopted automatic promotion in learning cycles, grade retention is not entirely eliminated, but limited to the final year of the cycles. The LDB furthermore sets fundamental criteria on how to organize promotion under any one regime: In every school year a minimum attendance of $75 \%$ of all school days must be fulfilled as a general requirement for promotion, so that grade retention is still permitted if students fall below a $75 \%$ minimum attendance. 
According to the legal framework of the LDB the decision on the promotion regime and its exact specifications is taken on the state level. Automatic promotion was introduced at an early stage by the states of São Paulo, Minas Gerais and Paraná, to some extent in the state of Pernambuco and by the federal resolution SE No 4, 1/98 in all federal schools in Brazil. A recent federal resolution disallowed retention for the first three schools years in all schools in Brazil from 2011.

In the state of Minas Gerais the new regime has been established by state resolution No. 8.086 in 1997. It stresses the autonomy of each public school in the decision whether to continue with the annual repetition regime or to introduce automatic promotion. In the year 20001,449 out of 1,993 state schools had established automatic promotion with two initial three-year cycles. At the beginning of the school year 2004 the remaining 544 state schools switched to automatic promotion.

\subsection{Assignment to treatment}

Schools that adopted automatic promotion at the beginning of the year 2004 make up the treatment group and schools with automatic promotion (which have adopted automatic promotion since the year 2000) the control group. I focus on two cohorts of fourth graders, which I call the test cohorts 2003 and 2006 for which test scores are available. Chart 1 presents an overview of these two cohorts and the change in the organization of promotion for the control and treatment group.

When using this division into treatment and control group for comparison a sound understanding of the assignment process that leads to this division is essential. In the case of state schools in Minas Gerais the 46 regional authorities for education needed to propose a plan of implementation of automatic promotion for the schools under their administration. The decision for early adoption of the policy was made by each SRE in agreement with the state secretariat. The second wave was initiated by the SEE in an attempt to introduce automatic promotion universally in all schools. As the adoption of the policy is not randomized across schools in an experimental setting, treatment and control schools may not be balanced in the distribution of school and student characteristics. Although the identification strategy used in this analysis does not rely on the distribution of covariates being balanced, it is generally reassuring to find school and mean student characteristics of treatment and control group to be very similar. Table A1, chart A and B present descriptive statistics of treatment and controls schools for 2003 and 2006. T-tests (and Chi-square for categorical variable) 
for the equality of means between treatment and comparison group, accounting for clustering on the SRE level, reveal only very few small but statistically significant differences. As sample size is partly reflected in the t-statistics, it is more useful to look at the normalized difference norm $-\operatorname{diff}=\frac{\overline{X_{0}}-\overline{X_{1}}}{\sqrt{S_{X, 0}^{2}+S_{X, 1}^{2}}}$ between means by treatment status as a scale-free measure of the balancing properties of the covariates (Imbens and Wooldridge 2009). The normalized difference is small for all covariates and never exceeds the absolute value $0.25,{ }^{11}$ suggesting that treatment and control schools are indeed very similar in terms of their physical school characteristics. Even more importantly, the normalized differences of mean student characteristics, which may indicate compositional differences of the student populations, are all very small and are far below the suggested rule-of-thumb value of $|0.25|$ in both years. Apart from mean age, which differs slightly as expected, ${ }^{12}$ no other variable reveals any considerable difference at the mean. The overlap in the covariate distributions can also be examined by looking at the distribution of the propensity score for the treatment and control group. Figure 1 shows the propensity score for the probability of treatment for the treatment and control group revealing substantial overlap in the multivariate distribution of covariates and a relatively similar pattern of the distribution of the propensity score for the treatment and control group. ${ }^{13}$

In addition, I estimate a linear probability model to determine whether there are systematic differences between schools that have adopted automatic promotion at different points in time and to learn what observable school characteristics - if any determine early adoption. The results are presented in table A6. The coefficients on the set of school characteristics are generally small and only very few are statistically significant. When including SRE controls even fewer variables show a significant effect and it is difficult to establish any systematic pattern.

Given the similarity of treatment and control schools with respect to school characteristics and the student composition, it is plausible to consider the assignment of schools to treatment and control groups as conditionally random.

\footnotetext{
${ }^{11}$ This is a rule of thumb suggested in Imbens \& Wooldridge 2009 to check the unconfoundedness assumption for the use of linear regression in estimating average treatment effects.

${ }_{12}$ Mean age is expected to differ as part of the treatment, which will be clarified in section 6.3.

${ }^{13}$ A formal test under the null for the equality of the distribution (Kolmogorov-Smirnov) of the propensity score is nevertheless rejected.
} 


\section{EMPIRICAL STRATEGY}

To estimate the treatment effect of the policy change I use a DiD estimator exploiting the variation in treatment status of schools over time, identifying an average treatment effect on individuals in schools assigned to treatment. The double difference approach is capable of removing biases resulting from permanent latent differences between treatment and control as well as biases resulting from common trends over time. The estimation in a regression setup allows including additional regressors on the individual and school level to improve precision and to test for the presence of omitted-school specific trends, in particular related to potential changes in the student composition. Identification requires that trends in student outcomes at treated and control schools would not be systematically different in the absence of treatment.

Under this identifying assumption, I estimate the effect of the introduction of automatic promotion on test scores of fourth graders by the following regression model:

$$
Y_{i s t}=\beta_{0}+d_{s}+d_{t}+\gamma d_{s t}+\beta_{1} Z_{i t}+\beta_{2} X_{s t}+\epsilon_{i s t}
$$

where $Y_{i s t}$ is the test score for individual $i$ in school $s$ at time $t, d_{s}$ is a school dummy which captures school-specific time invariant effects, $d_{t}$ is a time dummy which captures the common time trend of control and treatment group, $d_{s t}$ is the time/treatment-status interaction term containing information on the treatment status of schools, that varies over time. $\gamma$ in equation (1) is the coefficient of interest and reflects the average treatment effect of the introduction of automatic promotion on test scores of fourth graders. $Z_{i t}$ is a set of covariates controlling for individual characteristics. $X_{s t}$ denotes a set of exogenous covariates for class and school characteristics, including average socioeconomic characteristics of students, detailed school characteristics, ${ }^{14}$ the participation in federal, state and municipal educational programmes, ${ }^{15}$ teacher characteristics and other. ${ }^{16} \varepsilon$ is a stochastic error term.

\footnotetext{
${ }^{14}$ Specifically, the covariates include initial (first grade) enrolment, number of teachers at school, number of total staff (besides teaching staff), dummy variables describing the type of the premises used for the school, dummies for the availability and number of teaching material (e.g. overhead projectors, personal computers, TV and video sets etc.), the availability of computer and science labs, school kitchen, the quality of sanitary units, number of class rooms in- and outside the school and dummies for whether the school provides all 8 years of primary education.

${ }^{15}$ These programmes include National Minimum Income Programme, Free School Lunch programme, the provision of public school transportation, TV escola (a national education TV programme), other educational TV programmes, computer literacy programmes, and other state and municipal school programmes.
} 
Although non-random assignment of schools to treatment may lead to a correlation between assignment status and outcomes, this does not violate the common trend assumption as long as any differences that lead to the adoption of the policy are captured by the school-fixed effects. The common trend assumption may nevertheless be violated if selection into treatment was based on pre-treatment trends in school characteristics that differ between treatment and control. If, for example, schools with high performing students and low repetition rates adopt automatic promotion test scores and treatment status are correlated for reasons other than the treatment impact of automatic promotion. Unfortunately I do not have pre-treatment test score data to test directly for the common trend assumption. I nevertheless can investigate whether selection into treatment is based on pre-treatment differences in repetition rates. Table A2 reveals that pre-intervention repetition rates (from the 1997 school census before automatic promotion was introduced at any school) were virtually identical across treatment and control schools, so that there is little concern for self-selection of schools into treatment based on high or low repetition rates. The table also reports pre-treatment class size (averaged over grades 1-4) and pre-treatment student-teacher ratio (averaged over grades 1-4). While there is a small difference in class size of about one student, there is virtually no difference in the student teacher ratio and the normalized difference for both variables is well below |.25|. Classroom capacity constraints therefore were unlikely the driving factor behind the decision for early adoption. ${ }^{17}$ As I have pointed out earlier, the first wave of the policy adoption was initiated on the SRE level, which furthermore limits the potential for individual schools to select into treatment based on trends in test scores. The second wave was then determined by the decision of the CEE made for all remaining schools, so that there is virtually no scope for selection on a pre-treatment trend basis.

As the treatment regressor varies at the school level and test scores of students in the same school are likely correlated, for example because they share the same learning environment and/or are from the same neighbourhood, conventional standard errors may be misleading as they do not account for the grouped error structure. The robust

\footnotetext{
${ }^{16}$ This will also allow accounting for eligibility specific effects (Ashenfelter 1978). This way the above time invariant composition assumption can be relaxed to accommodate for the case where treatment and control group are expected to differ in covariates that may affect the outcome variable. ${ }^{17}$ Lam and Marteleto (2006) show that the demographic transition in Brazil in the 1990's had a strong impact on student cohort sizes and enrolment rates in Brazil, but this does not seem to be relevant in the context of this study.
} 
standard errors reported therefore allow for clustering on the school level (Donald and Lang 2007).

\section{ESTIMATION RESULTS}

\subsection{Main results}

The basic idea of the DiD strategy can be illustrated by a simple 2-by-2 table. Table 1 shows the levels and differences in test scores between treatment and control groups and the changes over time. The first row reports means before treatment (year=2003), when control schools were already under the automatic promotion regime and the treatment schools were still under the annual grade retention regime and the mean difference for the two groups. The entries in the first column reveal that schools that had already adopted automatic promotion have a mean score that is $7.05 \%$ of a standard deviation lower than schools that had not yet adopted the new regime in 2003. After the adoption of automatic promotion by schools of the treatment group this difference almost completely disappears and students at both groups have very similar average test scores and the difference in means is not statistically significant. Likewise, schools in the control group have very similar mean test scores over time with a difference that is not significantly different from zero. The lower right entry reports the simple DiD estimate, which can be interpreted as the causal effect of treatment under the above identifying assumptions. The adoption of automatic promotion leads to a decrease in test scores of $6.65 \%$ of a standard deviation. Almost the entire fraction of the $\mathrm{DiD}$ outcome originates from the pre-treatment difference between control and treatment schools. After the adoption of automatic promotion in treatment schools the difference between treated and control schools almost completely disappears.

This simple double difference can be amended in a regression framework following equation (1) to improve precision of the estimates and to be able to control for covariates and check the sensitivity of the estimates to their inclusion. Table 2 presents the estimates for different sets of controls. All specifications include school fixed effects and year dummies. School fixed effects capture stable unobserved characteristics of the schools and year dummies control for common trends in the test scores that are not related to treatment. Specification (1) of table 2 includes school controls, specification (2) controls for school and peer characteristics and specification (3) also includes individual level covariates. The estimates in all 
specifications reveal a stable negative effect of around $6 \%$ of a standard deviation and are very precisely estimated (1\% level of significance). Adding school level and peer controls reduces the negative effect, but the reduction is relatively small. Controlling additionally for individual characteristics delivers estimates of virtually the same size as the simple double difference in table 1 . The results reveal that the regime change from annual grade retention to automatic promotion has a significant negative impact on educational achievement on fourth graders in state schools in Minas Gerais. In the next section I will discuss the interpretation of the results.

6.2 Interpretation of the results and the disincentive of automatic promotion Table 4, column 1 reports the DiD estimates of the treatment on repetition rates for grades 1-4, following the tested cohorts of 2003 and 2006 over grades 1-4. The bottom entry for column 1 shows how the introduction of automatic promotion reduces the repetition rate in fourth grade by 0.086 . Prior to the policy change, about $10 \%$ of all students in treatment schools repeated fourth grade, but only about $2 \%$ did so after the introduction of automatic promotion. ${ }^{18}$ In this analysis I am interested in understanding whether the estimated effect on test scores can be explained by the elimination of the threat of retention for fourth grade students. ${ }^{19}$ The two cohorts of students at treatment schools face indeed very different incentives from the grade promotion regime; while the 2003 cohort is subject to grade retention, the 2006 cohort does not face the threat of being retained.

If the estimated effect is caused by a change in study incentives to avoid being retained, one would expect heterogeneous treatment effects along the test score distribution. Students in the lower tail of the distribution should be more heavily impacted by removing this incentive when compared to students in the upper tail, as these students should be less concerned about the possibility of retention. For that purpose I estimate equation (1) applying DiD to each quantile instead of the mean under analogue assumptions to the standard DiD (Koenker 2004, Athey and Imbens

\footnotetext{
${ }^{18}$ Repetition rates stay above zero because repetition is still possible when failing to achieve $75 \%$ minimum school attendance.

${ }^{19}$ As automatic promotion was introduced already at second grade, part of the estimated negative effect in fourth grade test scores could be due to the disincentive students faced already in second grade. Because of the repetition regime in third grade the effect is likely to be very small compared to the contemporaneous effect in fourth grade.
} 
2006, Firpo et al. 2009). ${ }^{20}$ Table 4 provides the quantile DiD estimates and reveals substantial differences in the treatment effect across the nine quantiles. The estimates range between -9.01 and -3.92 and are more pronounced in the lower half of the distribution, with the strongest effects centred on the fourth quantile. The effect of automatic promotion is much smaller for the top two quantiles and not statistically significant, yet still negative and non-negligible in magnitude. The inverse u-shaped distribution of effects is consistent with the interpretation of the estimates as disincentive effect of automatic grade promotion, such that the treatment effect is largest for students left of the centre of the distribution close to the assumed grade promotion threshold and smaller for high performing students that are unlikely to be retained. Similarly, for students at the very bottom of the distribution the effects are somewhat smaller with a coefficient of -7.49 but still above the mean treatment effect. The slightly smaller effect at the bottom of the distribution could be explained by either a different perception of the cost associated with retention or the fact that grade retention is a possibility for these low performing students regardless of their effort. ${ }^{21}$ There is some suggestive evidence that automatic promotion indeed directly impacts the behaviour of students and reduced their study effort. Column (1) of table A3 in annex reports the effect of the policy introduction on the propensity of students doing their homework. ${ }^{22}$ The DiD estimates show that after the introduction of automatic promotion fewer of the children do their homework (a decrease of 0.014); the coefficient is only marginally significant though. Interestingly, the change in the retention regime also changes the parents' involvement with their children's homework. Column (2) of the table shows that parents are more likely to help with their children's homework (an increase of 0.022). This reveals that parents may well be aware of the disincentive from automatic promotion and they may try to counteract the potential reduction in their children's study effort. If anything, increased parental involvement would however bias the estimates in table 2 towards zero, rather than explain the estimated effect.

The distribution of treatment effects in table 4 is also consistent with an explanation based on changes in teacher incentives from automatic promotion. Teachers may for

\footnotetext{
${ }^{20}$ Recent applications of quantile panel methods include Havnes and Mogstad 2010, GamperRabindran, Khan and Timmins 2010 and Lamarche 2011.

${ }^{21}$ Separate estimates by socio-economic status as proxied by the number of books in the household do not reveal heterogeneous effects along that margin (results not reported).

${ }^{22}$ All of the outcome variables in table A3 are based on pupil reported behavioural responses of themselves, their parents and their teachers and should therefore be considered more cautiously.
} 
example focus less on students in the bottom half of the distribution if they previously cared about them being promoted. ${ }^{23}$ Information on whether teachers assign and correct homework may shed some light on potential teacher responses to automatic promotion. Columns (3) and (4) of table A3 report the DiD estimates for teachers assigning and correcting homework respectively. Both coefficients are very close to zero and not statistically significant so that there is no evidence that teachers respond systematically to automatic grade promotion. ${ }^{24}$

\subsection{Changes in the student composition}

For the interpretation of the estimates as disincentive effect, any possible channel of effect of automatic promotion on outcomes - other than the disincentive effect - has to be precluded. Most importantly, potential changes in the composition of students in treatment and control schools over time could systematically lower test scores rather than the changes in incentives reducing the effort of students. Because there is grade retention in control and treatment schools in both periods at the end of third grade this leads to a positive selection of the students entering into fourth grade in both treatment and control schools and this mechanically limits the potential for changes in the student composition. In the section $6.4 \mathrm{I}$ will discuss the implications of this in detail.

Table 6 reports DiD estimates for a range of mean socioeconomic variables; for each outcome variable I have fitted a separate regression including school fixed effects and year dummies. Only the coefficients on the mean number of fridges per household and on mean age are statistically significant. All other indicators of the socioeconomic composition are not affected by the introduction of automatic promotion, which is very reassuring. While the coefficient for the mean number of fridges per household is very small and may be due to some spurious correlation, the significant reduction in mean age by about one month is more relevant and it is important to understand the source of this reduction in age and its consequence for the interpretation of the result.

This reduction in age is caused by the difference in the inflow of repeaters in fourth grade at the treatment schools before and after treatment. Whereas treatment schools

\footnotetext{
${ }^{23}$ Teachers may equally worry about the lost incentive for students and target their effort on the most affected students, so that a potential teacher response may go either way.

${ }^{24}$ Section 6.8 looks separately at class size as another teaching input.
} 
still received an inflow of repeaters from fourth grade of the previous year at the beginning of the year 2003, there was no such inflow of repeaters in 2006, which leads to the reduction in mean age, as repeaters are on average one year older. Table 8 , column 2 shows the DiD estimate of the policy change on the net inflow of students from first to fourth grade and from first to third grade in column (1). Whereas the coefficient in column (1) is very small, negative and not statistically significant, the coefficient for the net inflow of students including the inflow of repeaters from the previous year at the beginning of fourth grade is sizeable, positive and very precisely estimated (column (2)). Looking at the direct effect of the inflow of repeaters on mean age of the cohort reveals that this almost exactly explains the age effect estimated in table $6 .^{25}$ This means that the composition is altered due to treatment and it is important to understand the potential bias of the compositional change on mean achievement.

Even assuming a positive effect of repetition on educational outcomes of repeaters, ${ }^{26}$ it is very plausible to assume that average performance of repeaters is still below the mean performance of non-repeaters in the test cohort, as repeaters are selected as the lowest performers in fourth grade in the preceding year. ${ }^{27}$ How does this differential inflow affect the outcome variable of interest? As there was an inflow of such low performing students in 2003, but not in 2006 the results for the disincentive effect of automatic promotion are, if anything, biased towards zero and the reported coefficients in table 2 (chart A) need to be regarded as a lower bound of the true effect. Unfortunately, there is no direct information in the student questionnaire on whether and when students were retained. I can nevertheless use individual age to single out repeaters to some extent. A regression sensitivity analysis that includes individual age as a control variable may give an idea about the size of the bias from the differential inflow of repeaters. Adding individual age to specification (1) leads to an increase in the negative effect of about $20 \%$ to $-7.97 \%$ of a standard deviation compared to $-6.65 \%$ without controlling for age, reported in chart B of table 2 . Controlling for individual age in specification (2) and (3) leads to a very similar increase of $20 \%$ of the effect to $-7.33 \%$ and $-6.77 \%$, respectively.

\footnotetext{
25 Assuming that they are about one year older the inflow of repeaters at fourth grade leads to a decrease of mean age of the cohort of 36 days compared to the estimated effect on mean age of 39 days.

${ }^{26}$ And a direct effect related to age, as repeaters are one year due to repeating the grade.

${ }^{27}$ This is confirmed by the findings elsewhere; see Manacorda (2012) for example.
} 
An alternative way of investigating the importance of the bias for all specifications is to restrict the estimations to students that have never repeated by excluding all students outside the target age range of fourth graders. Once students from the additional inflow at fourth grade from the sample are removed, this leaves a sample of students that have never repeated. ${ }^{28}$ Chart A of table 5 reports the results for the same specifications as in table 2, but restricts the sample to students in the target age range for fourth graders. By restricting the sample in this way the coefficients exceed the estimates of the original full sample in all specifications by around $30 \%$. The estimated effect is a further 11-16\% larger compared to the estimates in chart B of table 2. Restricting the sample to repeaters (chart B, table 5) reveals a negative effect that is considerably smaller and no longer statistically significant. The number of excluded students is nevertheless larger than what could be explained by excluding fourth grade repeaters only, as removing overage students from the sample also removes students that have repeated at third grade. As repetition is equally possible in all schools at third grade, the additional increase in the estimates is therefore not necessarily related to treatment. The increase rather suggests that the incentive of grade retention may have a different impact on previous repeaters compared to students that have never repeated a grade. The cost of repetition is likely highest for students that have not previously repeated. In contrast the cost of being retained again is smaller for previous repeaters, as they may already have suffered stigmatization and have already been separated from their original peer group. The difference in results for the restricted sample therefore may not only reflect the correction for the differential inflow of repeaters at fourth grade, but may also more generally reflect heterogeneous effects on repeaters and non-repeaters.

A more comprehensive analysis of the sensitivity of the estimates to the inclusion of age controls is provided in table A4 in the annex. I present different specifications of equation (1) with and without controlling for individual age for the full sample (chart A) and the age restricted sample in chart B. The results support the previous findings. Adding individual age as control (columns 4, 6 and 8) strengthens the negative effect in the full and restricted sample for all the different specifications.

\footnotetext{
${ }^{28}$ Nevertheless I cannot distinguish repeaters from students that have enrolled late at first grade. With rather strict enforcement of the enrolment age in Minas Gerais and the incentives to parents to enrol their children based on Bolsa Família conditions, late enrolment is nevertheless rather limited.
} 
Besides the direct effect on the composition, there may be an indirect effect on students of having repeaters in the class room. Repeaters may impose a negative externality on their peers because their achievement is lower or because they may be more disruptive in class (Lazear 2001). Lavy, Paserman and Schlosser (2012) elaborate on the extent of ability peer effects associated with repeaters and show that academic performance and behaviour of repeaters may be responsible for the negative effect. By adding peer age in the DiD specification I can control for potential peer effects from the differential inflow at fourth grade. Adding peer age as control only moderately increases in size the coefficients in specification 1 and 2 in chart $\mathrm{C}$ of table 2. Columns 2 and 5 in charts A and B of table A4 reveal that the inclusion of peer age only has a minor effect when controlling for other peer variables and does not strengthen the estimates of the treatment effect suggesting that there is no noteworthy bias on the estimates. If anything, a negative peer effect of repeaters, as suggested in the literature, would lead to an underestimation of the effect.

Conditioning on individual age and restricting the sample to non-repeaters reveals that the differential inflow at fourth grade changes the composition of students in a way that underestimates the true effect of automatic promotion by not taking into account the net inflow of repeaters into fourth grade in 2003. The size of the downward bias ranges between $20 \%$ and $30 \%$. The estimates for the restricted sample should nevertheless be considered with caution, as the disincentive of automatic promotion may have differential impact on previous repeaters and non-repeaters.

\subsection{Introduction of automatic promotion at second grade}

Because of the introduction of automatic promotion in treatment schools at second grade of the cohort of interest, this potentially may also have an impact on the composition of students. Table 4 reveals how repetition rates from first to fourth grade of the theoretic test cohorts are affected by the policy introduction. The estimates for first and third grade show no effect of the treatment as expected. Rates at first grade are unaffected with the policy change occurring only in the subsequent year and rates in third grade are unaffected as the final year of the cycle remains with grade retention for both cohorts in treatment and control group. The estimate for the impact on the second grade reveals how the policy introduction lowers the repetition rate by almost $12 \%$ at second grade in 2004 . The potential threat to the interpretation of the results arises from the fact that by introducing automatic promotion at second 
grade for the 2006 exam cohort, this cohort may be "contaminated" by low performers that would have been removed in the absence of treatment. The mean repetition rate for second grade at treatment schools drops from 12.8\% (2003 exam cohort) to $3.1 \%$ (treatment cohort). Rather than looking at second grade repetition only, in- and outflows in each grade up to the end of third grade have to be considered when examining the effect of the adoption of automatic promotion on the student composition. Looking at overall student flows of the test cohorts reveals that the negative selection has largely cancelled out when the test cohort enters fourth grade in 2006. In particular, repetition in third grade plays an important role here. The first column of table 8 reports the effect of the policy introduction on the net flow taking into account in- and outflows over grades 1-3. The net inflow due to the introduction of automatic promotion is very close to zero and not statistically significant. This is mainly based on two factors: Focussing only on treatment schools, table A5 shows that repetition rates at third grade actually increased by about $4.3 \%$ for the 2006 exam cohort, which filters out a substantial fraction of the low-performers already. Furthermore, third grade repetition rates for the two cohorts have to be compared with caution, as these may have a different impact on removing low-performers from the previous year depending on the inflow of students into third grade at the beginning of the year. Considering net-flows, the composition of 2003 and 2006 cohorts are practically unaffected at the beginning of fourth grade. As mentioned earlier, the socioeconomic composition between the cohorts (table 6) is virtually unaltered by treatment, which supports the premise, that the policy introduction does not change the composition of students up to fourth grade.

This is also corroborated by the fact that almost the entire fraction of the DiD result arises from the ex-ante difference between treatment and control group in 2003, rather than from the difference after treatment. The results for the simple difference over time of the control schools and the difference between control and treatment schools after treatment in 2006 are very small and not significant at conventional levels.

As I have pointed out before, introduction of automatic promotion in second grade may also have a separate disincentive effect already at second grade. This separate disincentive effect is likely to be small, because of grade retention in the subsequent grade and general decay of the effect over time. The estimated effect at fourth grade 
can nevertheless be considered the composite effect of the disincentives over the two grades.

\subsection{Effect of the policy change on drop-out rates}

The effect of retention on student drop-out has been studied elsewhere in the literature (see Jacob and Lefgren 2004, 2009, Manacorda 2012). If the introduction of automatic promotion has an effect on drop-out rates in grades prior to fourth grade, this may change unobserved student characteristics that cannot be controlled for. I estimate the effect of the introduction of automatic promotion on drop-out rates in a DiD specification similar to equation (1) as $Y_{s t}=\beta_{0}+d_{s}+d_{t}+\gamma d_{s t}+\epsilon_{s t}$ (2), using aggregated data from the school census. Column (2) of table 4 reports the coefficients for each grade. Drop-out rates in second grade are unaffected by the policy change. ${ }^{29}$ The treatment nevertheless has a small effect on drop-out rates at third grade, by reducing the rate by half a percent. This is equivalent to a mean reduction of 0.31 students per school/cohort and presumably negligible in its potential impact on mean test scores.

\subsection{Effect of the policy change on school transfer rates}

Another potential source for compositional changes is related to student mobility between schools. Parents that expect a negative effect of automatic promotion on their children may for instance want to move their children to a school with grade retention. In Minas Gerais the possibility for switching public schools is limited as enrolment is mainly based on residence and a single public school often serves the local neighbourhood. Given very substantial fees at private schools it is also unlikely that parents move their children into private schools to avoid a specific grade promotion regime. As the policy was introduced while the cohort of interest was in second grade the incentive for parents to move their children is further reduced. To test for any effect of the policy change on between-school mobility I estimate the effect of the introduction of automatic promotion on student transfer rates using the same framework as in the previous section. Columns (3) and (4) of table 4 report point estimates for outgoing and incoming transfer rates that are close to zero and not

\footnotetext{
${ }^{29}$ First grade repetition rates are also unaffected as predicted, because the policy change only takes effect after first grade. This is a relevant observation as it shows that there are no anticipatory effects from schools to the introduction to the policy change.
} 
significant for any grades, so that there is no evidence that student mobility has an impact on the student composition.

\subsection{Systematic test taking behaviour}

Although participation in PROEB is mandatory on the school and individual level, some students fail to attend the test. ${ }^{30}$ If the propensity to show up at the exam is related to the capacity of the student and to the treatment status of the school, this may bias the estimates. This might be induced by strategic behaviour of school administrators or teachers trying to manipulate the mean test scores of their school in the PROEB exam. If this is systematically linked to treatment status this could bias the estimates. Notably, individually identified test results are not available to the schools and PROEB test scores are not used by schools for the grade promotion decisions. I use information from the official student numbers in each school from the school census and compare these to the number of students participating in PROEB. I estimate equation (2) using the difference between the two figures as outcome variable. Table 7 presents the results from the regression. The coefficient is very small (0.119 students) and not statistically significant so that there is no evidence for systematic absence of students from the test.

\subsection{Effect of the policy change on class size}

There may be other teaching inputs that could be affected by the policy change; for example a reduction in retention rates may affect class-size, which in turn may have an impact on outcomes. There is a comprehensive literature on the effect of class size on student performance but the overall picture about class-size effects remains rather unclear. ${ }^{31}$ To rule out that the estimates are biased by an effect of the policy on classsize I test for changes in class-size for each grade induced by the policy change for the cohorts of interest and column (5) of table 4 reports the DiD results. There is no evidence for an effect of the policy change on class-size in any grade, so that estimates on test scores are unlikely biased by treatment induced class-size effects. Even under the assumption that the introduction of automatic promotion releases other school resources that could be allocated to fourth grade students (for which

\footnotetext{
${ }^{30}$ The participation rate for the 2003 and 2006 wave of PROEB is around 95\% as participation is strictly enforced and absence is only permitted in case of illness.

${ }^{31}$ See Hoxby (2000) and Angrist \& Lavy (1999) for two prominent studies on class size effects.
} 
there is no evidence in the present analysis) this would lead to underestimating the true impact of the disincentive created by automatic promotion.

The fact that none of the above estimates (for repetition rates, drop-out rates, classsize, transfer rates) reveal any significant effect for first grade estimates is in itself an important falsification exercise. All these estimates are based on a placebo-treatment as the first grade of the 2006 exam cohort was not yet affected by the policy introduction. This also indicates that there are no anticipatory effects of the schools in respect to the imminent introduction of automatic promotion that may affect student outcomes at a later stage.

\section{CONCLUSIONS}

Existing empirical work on grade retention has to date focused on analysing the direct effect of retention on repeaters. The focus on the ex-post effects may nevertheless neglect an important effect of the grade retention regime that works through incentives to study on a larger range of students than repeaters only. The introduction of automatic promotion removes the incentives linked to the threat of retention and in this paper I use exogenous variation in the timing of the policy adoption in public primary schools in the Brazilian state of Minas Gerais to obtain causal estimates of automatic promotion.

Using a DiD approach I find a negative effect of about $6,7 \%$ of a standard deviation, significant at the $1 \%$ level. Controlling for individual age strengthens the negative effect by about $20 \%$, which gives an idea about the size of the bias associated with the differential inflow of repeaters into fourth grade before and after treatment. The estimated effect of the introduction of automatic promotion is of non-negligible size. Considering that automatic promotion may have a negative effect in several grades, the overall impact of the automatic promotion regime may lead to considerable loss of academic achievement over the eight years of primary school. Quantile DiD estimates yield an important insight into the distribution of effects. The quantile DiD estimates reveal that a large set of students is impacted by the policy change and not only the least performing students. The inverse u-shape of effects along the test score distribution is consistent with an interpretation of the estimates as disincentive effect of automatic promotion. Some further suggestive evidence on student responses 
support this interpretation. Other potential channels, in particular related to changes in the student composition, can be ruled out.

The estimation of a disincentive effect associated with automatic promotion closes a gap in the literature on the effects of grade retention and helps to explain the persistence of repetition regimes in many countries. Grade retention reduces internal flow efficiency at schools and is a costly policy, but may have a positive effect on academic achievement through a deterrence effect. Rather than focusing only on the effect on repeaters, attempts to assess the costs and benefits of grade retention therefore need to take into account the effects on non-repeaters as well.

This is important in the light of the universal introduction of automatic promotion in all primary schools in Brazil that came into effect by federal legislation in 2011. Although the Brazilian experience may not be completely transferable to other countries - often with lower repetition rates - the findings may nevertheless be relevant for countries facing pressures to meet the Millennium Development Goal of universal primary education and who may regarding the introduction of automatic promotion as a suitable way to reduce repetition rates and increase school completion rates. 
Acknowledgements

I am very grateful to Marco Manacorda for his thoughtful advice. I also thank David Card, Jefferson Mainardes, Imran Rasul and seminar participants at University College London, Queen Mary, the International Conference on the Economics of Education in Zurich 2008, the Spring Meeting of Young Economists 2010, and the Congress of the European Economic Association 2010 for valuable comments. I am grateful to the Secretariat of Education in Minas Gerais, the Brazilian Ministry of Education and the National Institute for Educational Studies and Research (INEP) for the data. I thank Juliana Riani and Jorge Rondelli for assistance with obtaining the data. I am also grateful to the Editor and two anonymous referees for their comments which have improved the paper considerably. The usual disclaimer applies. 


\section{LITERATURE}

Angrist, J.D., Bettinger, E., Bloom, E., King, E., Kremer, M., 2002. Vouchers for Private Schooling in Colombia: Evidence from Randomized Natural Experiments. American Economic Review, 92(5), 1535-1558.

Angrist, J.D., Lavy, V., 1999. Using Maimonides' Rule to Estimate the Effect of Class Size on Scholastic Achievement. Quarterly Journal of Economics. 114(2), 533-575.

Ashenfelter, O., 1978. Estimating the Effect of Training Programs on Earnings. Review of Economics and Statistics, 60(1), 47-57.

Athey, S., Imbens, G. 2006. Identification and Inference in Nonlinear Difference-inDifferences Models. Econometrica, 74(2), 431-497.

De Janvry, A., Finan, F., Sadoulet, E., 2006. Evaluating Brazil's Bolsa Escola Program: Impact on Schooling and Municipal Roles. Unpublished manuscript.

De Mello, L., Hoppe, M., 2005. Education Attainment in Brazil: the Experience of FUNDEF. OECD Economics Department Working Papers 424.

Donald, S., Lang, K., 2007. Inference with Differences-in-Differences and Other Panel Data. Review of Economics and Statistics, 89(2), 221-233.

Dong, Y., 2009. Kept Back to Get Ahead? Kindergarten Retention and Academic Performance. European Economic Review, 54(2), 219-236.

Eide, E., Showalter, M., 2001. The Effect of Grade Retention on Educational and Labor Market Outcomes. Economics of Education Review, 20(6), 563-576.

Firpo, S., Fortin, M., Lemieux, T. 2009. Unconditional Quantile Regressions. Econometrica, 77(3), 953-973.

Gamper-Rabindran, S., Khan, S., Timmins, C. 2010. The Impact of Piped Water Provision on Infant Mortality in Brazil: A Quantile Panel Data Approach. Journal of Development Economics, 92(2), 188-200.

Glick, P., Sahn, D., 2010. Early Academic Performance, Grade Repetition, and School Attainment in Senegal: A Panel Data Analysis. World Bank Economic Review, 24(1), 93-120.

Gomes-Neto, J.B., Hanushek, E.A., 1994. Causes and Consequences of Grade Retention: Evidence from Brazil. Economic Development and Cultural Change, 43(1), 117-48.

Havnes, T., Mogstad, M. 2010. Is Universal Child Care Levelling the Playing Field? Evidence from Non-Linear Difference-in-differences. IZA Discussion Paper No. 4978.

Holmes, T.C., 1989. Grade Level Retention Effects: A Meta-Analysis of Research Studies. In: Flunking Grades: Research and Policies on Retention, ed. Lorrie A. Shepard and Mary L. Smith, 16-33. London: Falmer Press.

IBGE (Brazilian Institute of Geography and Statistics), 2007. Contas Nacionais No. 21: Contas Regionais do Brasil 2002-2005. Rio de Janeiro.

Imbens, G., Wooldridge, J., 2009. Recent Developments in the Econometrics of Program Evaluation. Journal of Economics Literature, 47(1), 5-86.

INEP (National Institute for Educational Studies and Research). 2007. IDEB - Prova Brasil/Saeb 2007. Brasilia.

Jacob, B.A. 2005. Accountability, Incentives and Behaviour: Evidence from School Reform in Chicago. Journal of Public Economics, 89(5-6), 761-796. 
Jacob, B., Lefgren, L., 2004. Remedial Education and Student Achievement: a Regression-Discontinuity Analysis. Review of Economics and Statistics, 86(1), 226-44.

Jacob, B., Lefgren, L., 2009. The Effect of Grade Retention on High School Completion. American Economic Journal: Applied Economics, 1(3), 33-58.

Koenker, R. 2004. Quantile Regression for Longitudinal Data. Journal of Multivariate Analysis, 91(1), 74-89.

Lam, D. and Marteleto, L. 2006. Small Families and Large Cohorts: The Impact of the Demographic Transition on Schooling in Brazil. In: Lloyd, C., Behrman, J., Stromquist, N., and Cohen, B. (eds). The Changing Transition to Adulthood in Developing Countries. The National Academic Press, Washington.

Lamarche, C. 2011. Measuring the Incentives to Learn in Colombia Using New Quantile Regression Approaches. Journal of Development Economics, 96(2), 278-288.

Lavy, V., Paserman, D., Schlosser, A., 2012. Inside the Black Box of Ability Peer Effects: Evidence from Variation in Low Achievers in the Classroom. Economic Journal, 122(3), 208-237.

Lazear, E. 2001. Educational Production. Quarterly Journal of Economics, 116(3), 777-803.

Lindert, K., Linder, A., Hobbs, J., de la Brière, B., 2007. The Nuts and Bolts of Brazil's Bolsa Família Program: Implementing Conditional Cash Transfers in a Decentralized Context. Social Protection Discussion Paper 0709, World Bank.

Mainardes, J., 2010. Moving Away from a Graded System: a Policy Analysis of the Primary Education Organized in Cycles in Brazil. Lampert, Saarbrücken.

Manacorda, M., 2012. The Cost of Grade Retention. Review of Economics and Statistics, 94(2), 596-606.

Manski, C. 1993. Identification of Endogenous Social Effects: the Reflection Problem. Review of Economic Studies, 60(3), 531-542.

MEC (Brazilian Ministry of Education), 1996. Lei de Diretrizes e Bases da Educação National, No. 9394, Art. 24, December 1996, Brasilia.

OECD, 2005. OECD Economic Survey of Brazil 2005. Organization for Cooperation and Development, Paris.

Pino, I.R., Koslinki, M.C., 1999. Government Programs to Eliminate Repetition, School Dropout and Exclusion in Brazil. In: Schooling for Success: Preventing Repetition and Dropout in Latin American Primary Schools, ed. Laura Randall and Joan B. Anderson. New York: Sharpe.

UNESCO, 2008. EFA Global Monitoring Report. United Nations Educational, Scientific and Cultural Organization, Paris.

UNESCO. 2012. Opportunities lost: The impact of grade repetition and early school leaving. Global Education Digest 2012. United Nations Educational, Scientific and Cultural Organization, Paris. 
FIGURE 1: HISTOGRAM FOR THE PROPENSITY SCORE (YEAR 2003)

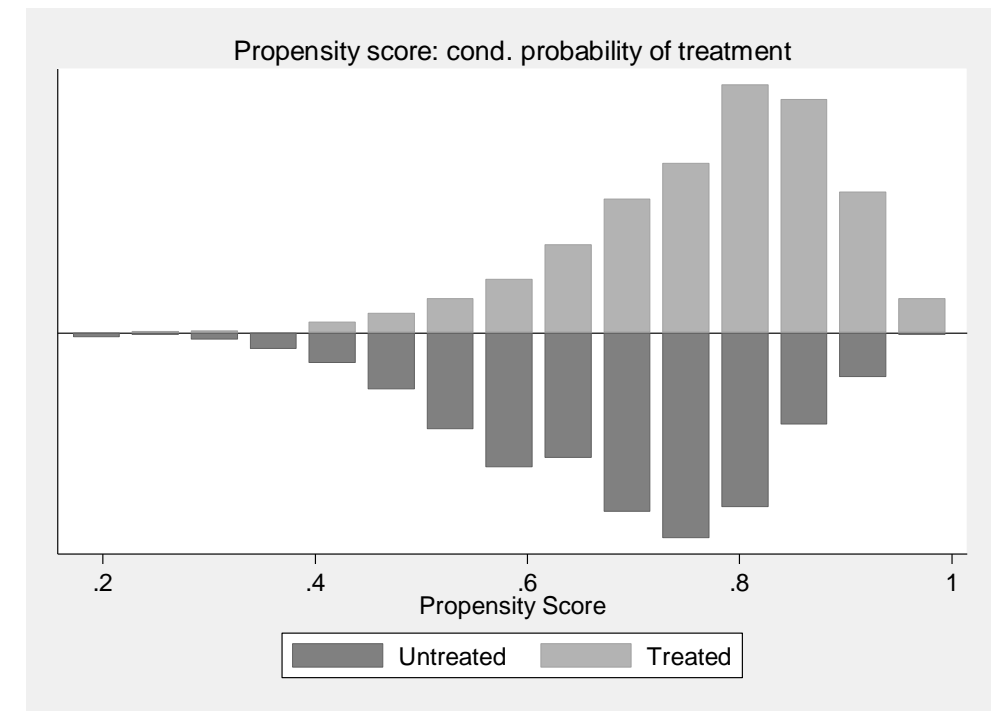

CHART 1: TREATMENT SCHEME

\begin{tabular}{lc|cccc}
\hline & $\begin{array}{c}\text { exam } \\
\text { cohort }\end{array}$ & & & & $\begin{array}{c}\text { PROEB } \\
\text { test }\end{array}$ \\
\hline Grade & & $\begin{array}{c}1^{\text {st }} \\
\text { grade }\end{array}$ & $\begin{array}{c}2^{\text {nd }} \\
\text { grade }\end{array}$ & $\begin{array}{c}3^{\text {rd }} \\
\text { grade }\end{array}$ & $\begin{array}{c}4^{\text {th }} \\
\text { grade }\end{array}$ \\
\hline \multirow{4}{*}{ Treatment schools } & 2003 & 1 & 1 & 1 & 1 \\
& year & 2000 & 2001 & 2002 & 2003 \\
& 2006 & 1 & 0 & 1 & 0 \\
\hline \multirow{4}{*}{ Control schools } & year & 2003 & 2004 & 2005 & 2006 \\
& 2003 & 0 & 0 & 1 & 0 \\
& year & 2000 & 2001 & 2002 & 2003 \\
& 2006 & 0 & 0 & 1 & 0 \\
\hline
\end{tabular}

Notes: Testing takes place for all students at the end of $4^{\text {th }}$ grade. The cohorts are denoted according to the year in which they are tested through PROEB. 1 denotes grades with grade retention, 0 denotes grades with automatic promotion. 
TABLE 1: TEST SCORE MEANS IN TREATMENT AND CONTROL SCHOOLS BEFORE AND AFTER THE ADOPTION IN THE TREATMENT SCHOOLS

\begin{tabular}{lcc|c}
\hline \hline & Before treatment & After treatment & $\begin{array}{c}\text { Change in mean } \\
\text { test scores }\end{array}$ \\
\hline Control schools & 498.48 & 498.99 & -0.51 \\
& $(1.55)$ & $(1.51)$ & $(2.01)$ \\
Treatment schools & 505.53 & 499.39 & 6.14 \\
& $(2.71)$ & $(2.59)$ & $(2.97)$ \\
\hline $\begin{array}{l}\text { Difference in mean test } \\
\text { scores }\end{array}$ & -7.05 & -0.40 & -6.65 \\
\hline
\end{tabular}

Notes: Mean outcomes for treatment and control before and after treatment. Standard errors, adjusted for clustering within SREs, are reported in parenthesis.

TABLE 2: MAIN ESTIMATION RESULTS AND SENSITIVITY TO AGE CONTROLS

Dependent variable: PROEB math test scores

Observations: 244,081 , number of clusters: 1,993

\begin{tabular}{lccc}
\hline & $(1)$ & $(2)$ & $(3)$ \\
\cline { 2 - 4 } Chart A & & & \\
Treatment effect & $-6.13^{* * *}$ & $-5.67 * * *$ & $-6.24 * * *$ \\
R-squared & $(2.03)$ & $(1.98)$ & $(2.04)$ \\
\cline { 2 - 4 } Chart B - adding individual age control & 0.01 & 0.01 & 0.17 \\
Treatment effect & $-7.33^{* * * *}$ & $-6.77 * * *$ & $-6.24 * * *$ \\
& $(2.11)$ & $(2.04)$ & $(2.04)$ \\
\cline { 2 - 4 } R-squared & 0.04 & 0.04 & 0.17 \\
\hline Chart C - adding peer age control & & & \\
Treatment effect & $-6.46^{* * *}$ & $-5.67 * * *$ & $-6.24 * * *$ \\
& $(2.02)$ & $(1.98)$ & $(2.04)$ \\
\cline { 2 - 4 } R-squared & 0.01 & 0.01 & 0.17 \\
\hline School fixed effects & yes & yes & yes \\
Year dummies & yes & yes & yes \\
School level controls & yes & yes & yes \\
Peer characteristics controls & no & yes & yes \\
Individual characteristics controls & no & no & yes \\
\hline
\end{tabular}

Notes: $* * *$ denotes significance at $1 \%$. Robust standard errors, adjusted for clustering within schools, are reported in parenthesis. Specification (1) contains year dummies and school fixed effects, specification (2) additionally controls for a rich set of school characteristics (physical characteristics of the school and the class rooms, teaching material, teacher characteristics, participation in educational programmes etc.), specification (3) additionally controls for peer socio-economic characteristics at the school level and specification (4) also controls for individual characteristics. 
TABLE 3: EFFECT OF THE ADOPTION OF AUTOMATIC

PROMOTION ON STUDENT FLOWS AND CLASS-SIZE

\begin{tabular}{|c|c|c|c|c|c|}
\hline \multicolumn{6}{|c|}{ Dependent variable: } \\
\hline & Repetition rate & $\begin{array}{c}\text { Drop-out rate } \\
(2) \\
\end{array}$ & $\begin{array}{c}\text { Transfer-rate } \\
\text { outgoing } \\
(3) \\
\end{array}$ & $\begin{array}{c}\text { Transfer-rate } \\
\text { incoming } \\
(4)\end{array}$ & $\begin{array}{c}\text { Class-size } \\
(5) \\
\end{array}$ \\
\hline Grade 1 & $\begin{array}{l}-0.010 \\
(0.010)\end{array}$ & $\begin{array}{c}0.001 \\
(0.003)\end{array}$ & $\begin{array}{l}-0.005 \\
(0.007)\end{array}$ & $\begin{array}{c}0.007 \\
(0.008)\end{array}$ & $\begin{array}{c}0.692 \\
(0.363)\end{array}$ \\
\hline Grade 2 & $\begin{array}{l}-0.118^{* * *} \\
(0.010)\end{array}$ & $\begin{array}{l}-0.002 \\
(0.003)\end{array}$ & $\begin{array}{c}0.002 \\
(0.006)\end{array}$ & $\begin{array}{c}0.003 \\
(0.009)\end{array}$ & $\begin{array}{c}0.828 \\
(0.422)\end{array}$ \\
\hline Grade 3 & $\begin{array}{l}-0.019 \\
(0.011)\end{array}$ & $\begin{array}{l}-0.005 * * \\
(0.002)\end{array}$ & $\begin{array}{l}-0.002 \\
(0.003)\end{array}$ & $\begin{array}{c}0.007 \\
(0.009)\end{array}$ & $\begin{array}{c}0.502 \\
(0.416)\end{array}$ \\
\hline Grade 4 & $\begin{array}{l}-0.086 * * * \\
(0.007)\end{array}$ & $\begin{array}{l}-0.005 \\
(0.004)\end{array}$ & $\begin{array}{l}-0.007 \\
(0.004)\end{array}$ & $\begin{array}{c}0.006 \\
(0.008)\end{array}$ & $\begin{array}{c}0.252 \\
(0.336)\end{array}$ \\
\hline \multicolumn{6}{|c|}{ Number of schools: 1993 , years 2000-2006, average cohort size: 61.24} \\
\hline \multicolumn{6}{|c|}{$\begin{array}{l}\text { Notes: } * * * \text { denotes significance at } 1 \%, * * \text { denotes significance at } 5 \% \text {. The coefficients report the effect of introducing } \\
\text { automatic promotion on the dependent variables for } 1^{\text {st }} \text { to } 4^{\text {th }} \text { grade using data from the school census } 2000-2006 \text { following } \\
\text { the theoretical test cohorts. For each grade a separate regression has been fitted estimating the effect corresponding to } \\
\text { equation }(1) \text { as } Y_{s t}=\beta_{0}+d_{s}+d_{t}+\gamma d_{s t}+\epsilon_{s t} \text {. The regression estimates are weighted by school cohort size and include } \\
\text { year dummies }\left(d_{t}\right) \text { and school fixed effects }\left(d_{s}\right) \text {. Robust standard errors, adjusted for clustering within } 46 \text { SREs, are reported in } \\
\text { parenthesis. }\end{array}$} \\
\hline
\end{tabular}

TABLE 4: QUANTILE TREATMENT EFFECTS

\begin{tabular}{lccccccccc}
\hline \multicolumn{1}{l}{ Dependent variable: PROEB test scores } & \multicolumn{10}{l}{} \\
\hline Quantile & $(1)$ & $(2)$ & $(3)$ & $(4)$ & $(5)$ & $(6)$ & $(7)$ & $(8)$ & $(9)$ \\
\hline Treatment effect & 1 & 2 & 3 & 4 & 5 & 6 & 7 & 8 & 9 \\
& $-7.49^{* *}$ & $-8.44^{* * *}$ & $-8.53^{* * *}$ & $-9.01^{* * *}$ & $-8.54^{* * *}$ & $-6.82^{* *}$ & $-5.12^{*}$ & -3.92 & -4.22 \\
& $(2.94)$ & $(2.66)$ & $(2.63)$ & $(2.61)$ & $(2.66)$ & $(2.75)$ & $(2.85)$ & $(3.07)$ & $(3.58)$ \\
\hline
\end{tabular}

Notes: $* * *$ denotes significance at $1 \%, * *$ significance at $5 \%, *$ significance at $10 \%$. The coefficients report the quantile differences-in-difference treatment effects for nine quantiles of the test score distribution. The regressions include year dummies and school fixed effects. Bootstrapped standard errors (200 repetitions) adjusted for clustering on the school level are reported in parenthesis. 
TABLE 5: ESTIMATION RESULTS FOR RESTRICTED AGE RANGES

Dependent variable: PROEB test scores

Number of clusters: 1,993
(1)
(2)
(3)

Chart $\mathrm{A}$ - students in target age range for $4^{\text {th }}$ grade

\begin{tabular}{lccc} 
Treatment effect & $-8.07 * * *$ & $-7.50^{* * *}$ & $-7.22 * * *$ \\
R-squared & -2.26 & -2.23 & -2.25 \\
\cline { 2 - 4 } Observations & 0.01 & 0.01 & 0.13 \\
\cline { 2 - 4 } & \multicolumn{3}{c}{149,223} \\
\hline Chart B - repeaters (outside target age range) & & \\
Treatment effect & -3.42 & -2.89 & -3.29 \\
& $(2.50)$ & $(2.50)$ & $(2.42)$ \\
\cline { 2 - 4 } R-squared & 0.01 & 0.00 & 0.08 \\
\cline { 2 - 4 } Observations & \multicolumn{3}{c}{88,657} \\
\hline School fixed effects & yes & yes & yes \\
Year dummy & yes & yes & yes \\
School level controls & yes & yes & yes \\
Peer characteristics controls & no & yes & yes \\
Individual characteristics controls & no & no & yes \\
\hline
\end{tabular}

Notes: *** denotes significance at $1 \%$. The above samples exclude students that are below the target age range. Robust standard errors, adjusted for clustering within schools, are reported in parenthesis. Specification (1) only includes year dummies and school fixed effects, specification (2) additionally controls for a rich set of school characteristics (physical characteristics of the school and the class rooms, teaching material, teacher characteristics, participation in educational programmes etc.), specification (3) additionally controls for peer socio-economic characteristics at the school level and specification (4) also controls for individual characteristics. 
TABLE 6: EFFECT OF THE ADOPTION OF AUTOMATIC PROMOTION ON THE SOCIO-ECONOMIC COMPOSITION

\begin{tabular}{lcc}
\hline \hline Dependent variables: & Coefficient & Robust standard error \\
\hline Proportion of white students & 0.010 & $(0.008)$ \\
Proportion of mixed students & -0.009 & $(0.012)$ \\
Proportion of black students & 0.003 & $(0.005)$ \\
Proportion if Asian students & -0.004 & $(0.003)$ \\
Proportion of indigenous students & -0.000 & $(0.003)$ \\
Mean age (in years) & $-0.106^{* * *}$ & $(0.022)$ \\
Mean male students & -0.005 & $(0.007)$ \\
HH wealth index & 0.007 & $(0.025)$ \\
Bathroom mean & 0.018 & $(0.009)$ \\
TV mean & 0.004 & $(0.007)$ \\
Video mean & 0.007 & $(0.012)$ \\
Radio mean & -0.010 & $(0.012)$ \\
Fridge mean & $0.016^{* *}$ & $(0.007)$ \\
Freezer mean & -0.014 & $(0.019)$ \\
Washing machine mean & 0.012 & $(0.010)$ \\
Car mean & 0.011 & $(0.009)$ \\
Computer mean & -0.004 & $(0.008)$ \\
Books mean & 0.026 & $(0.014)$ \\
\hline n=1993 & &
\end{tabular}

Notes: denotes $* *$ significance at 5\% level, $* * *$ significance at $1 \%$ level. All estimates refer to school means or proportions at the school level. All data is taken from the socioeconomic questionnaire of PROEB. For each dependent variable the effect is estimated separately in a regression corresponding to equation (1) as $Y_{s t}=\beta_{0}+d_{s}+d_{t}+\gamma d_{s t}+$ $\epsilon_{s t}$. The regression estimates are weighted by school cohort size and include a year dummies $\left(d_{t}\right)$ and school fixed effects $\left(d_{s}\right)$. Robust standard errors, adjusted for clustering within SREs, are reported in parenthesis. All estimates are weighted by school cohort size.

\section{TABLE 7: EFFECT OF THE ADOPTION OF AUTOMATIC PROMOTION ON PARTICIPATION IN PROEB}

\begin{tabular}{|c|c|c|c|}
\hline \multicolumn{4}{|c|}{$\begin{array}{l}\text { Dependent variable: difference between official student numbers and PROEB } \\
\text { participation numbers }\end{array}$} \\
\hline Coefficient & R-squared within & R-squared between & R-squared overall \\
\hline 0.119 & 0.59 & 0.02 & 0.04 \\
\hline$(0.976)$ & & & \\
\hline
\end{tabular}

Notes: The coefficient reports the effect of the introduction of automatic promotion on the difference of the number of students according to the school census and the PROEB test. The effect is estimated by a regression corresponding to equation (1) as $Y_{s t}=\beta_{0}+d_{s}+d_{t}+$ $\gamma d_{s t}+\epsilon_{s t}$. The estimates are weighted by school cohort size and include year dummies $\left(d_{t}\right)$ and school fixed effects $\left(d_{s}\right)$. Robust standard errors adjusted for 46 clusters (on SRE level) are reported in parenthesis. 
TABLE 8: EFFECT OF POLICY ADOPTION ON STUDENT NET FLOW

(1)

(2)

\begin{tabular}{ccc}
\hline & $\begin{array}{c}\text { Student net inflow up } \\
\text { to } 1^{\text {st }}-3^{\text {rd }} \text { grade }\end{array}$ & $\begin{array}{c}\text { Student net inflow including } \\
4^{\text {th }} \text { grade }\end{array}$ \\
\hline Coefficient & -0.010 & $0.079 * * *$ \\
& $(0.015)$ & $(0.014)$ \\
\hline R-squared & 0.55 & 0.59 \\
\hline
\end{tabular}

Notes: $* * *$ denotes significance at $1 \%$. The coefficients report the effect of introducing automatic promotion on net flow (including in/outflow due to repetition using data from the school census 2000-2006. A separate regression has been fitted estimating the effect corresponding to equation (1) as $Y_{s t}=\beta_{0}+d_{s}+d_{t}+\gamma d_{s t}+\epsilon_{s t}$ for the two models. Model (1) refers to net flows including $2^{\text {nd }}$ and $3^{\text {rd }}$ grade, model (2) refers to net flows including $2^{\text {nd }}, 3^{\text {rd }}$ and $4^{\text {th }}$ grade. The regression estimates are weighted by school cohort size and include a year dummy $\left(d_{t}\right)$ and school fixed effects $\left(d_{s}\right)$. Robust standard errors adjusted for 46 clusters (on SRE level) are reported in parenthesis. 
TABLE A1: MEAN CHARACTERISTICS OF TREATMENT AND CONTROL GROUPS IN 2003 AND 2006 CHART A: PHYSICAL CHARACTERISTICS AND SCHOOL PROGRAMME PARTICIPATION

\begin{tabular}{|c|c|c|c|c|c|c|c|c|c|c|c|c|}
\hline \multirow[b]{3}{*}{$n=1993$} & \multicolumn{5}{|c|}{2003} & \multicolumn{7}{|c|}{2006} \\
\hline & \multicolumn{2}{|c|}{ Control } & \multicolumn{2}{|c|}{ Treatment } & \multirow[b]{2}{*}{ P-value } & \multicolumn{3}{|c|}{ Control } & \multicolumn{2}{|c|}{ Treatment } & \multirow[b]{2}{*}{$\mathrm{P}$-value } & \multirow[b]{2}{*}{$\begin{array}{c}\text { Norm- } \\
\text { diff }\end{array}$} \\
\hline & Mean & SD & Mean & SD & & $\begin{array}{c}\text { Norm- } \\
\text { diff }\end{array}$ & Mean & SD & Mean & SD & & \\
\hline Rural school & 0.885 & $(0.319)$ & 0.890 & $(0.313)$ & 0.788 & -0.011 & 0.885 & $(0.319)$ & 0.895 & $(0.307)$ & 0.544 & -0.023 \\
\hline State property & 0.918 & $(0.275)$ & 0.880 & $(0.325)$ & 0.020 & 0.089 & 0.907 & $(0.290)$ & 0.881 & $(0.324)$ & 0.106 & 0.060 \\
\hline Municipal property & 0.062 & $(0.242)$ & 0.093 & $(0.290)$ & 0.035 & -0.082 & 0.066 & $(0.249)$ & 0.090 & $(0.287)$ & 0.098 & -0.063 \\
\hline Private property & 0.020 & $(0.141)$ & 0.067 & $(0.161)$ & 0.414 & -0.220 & 0.024 & $(0.154)$ & 0.027 & $(0.163)$ & 0.696 & -0.013 \\
\hline School ownership & 0.901 & $(0.298)$ & 0.866 & $(0.340)$ & 0.040 & 0.077 & 0.907 & $(0.290)$ & 0.881 & $(0.324)$ & 0.106 & 0.060 \\
\hline Rented school & 0.014 & $(0.118)$ & 0.020 & $(0.140)$ & 0.393 & -0.033 & 0.010 & $(0.100)$ & 0.09 & $(0.138)$ & 0.164 & -0.469 \\
\hline Donated school & 0.085 & $(0.278)$ & 0.114 & $(0.317)$ & 0.068 & -0.069 & 0.082 & $(0.275)$ & 0.100 & $(0.300)$ & 0.261 & -0.044 \\
\hline Shared school & 0.197 & $(0.398)$ & 0.238 & $(0.426)$ & 0.060 & -0.070 & 0.197 & $(0.398)$ & 0.197 & $(0.398)$ & 10.00 & 0.000 \\
\hline Principal office & 0.875 & $(0.331)$ & 0.858 & $(0.350)$ & 0.324 & 0.035 & 0.865 & $(0.342)$ & 0.874 & $(0.332)$ & 0.625 & -0.019 \\
\hline Admin. office & 0.909 & $(0.287)$ & 0.937 & $(0.243)$ & 0.036 & -0.074 & 0.950 & $(0.219)$ & 0.952 & $(0.214)$ & 0.845 & -0.007 \\
\hline Teacher room & 0.813 & $(0.390)$ & 0.811 & $(0.392)$ & 0.912 & 0.004 & 0.827 & $(0.379)$ & 0.843 & $(0.363)$ & 0.382 & -0.030 \\
\hline School kitchen & 0.829 & $(0.377)$ & 0.824 & $(0.381)$ & 0.808 & 0.009 & 0.821 & $(0.384)$ & 0.821 & $(0.384)$ & 0.997 & 0.000 \\
\hline Refectory & 0.374 & $(0.484)$ & 0.440 & $(0.497)$ & 0.010 & -0.095 & 0.412 & $(0.493)$ & 0.464 & $(0.499)$ & 0.046 & -0.074 \\
\hline Food storage & 0.839 & $(0.368)$ & 0.856 & $(0.352)$ & 0.368 & -0.033 & 0.732 & $(0.443)$ & 0.718 & $(0.450)$ & 0.533 & 0.022 \\
\hline Computer lab & 0.237 & $(0.426)$ & 0.149 & $(0.356)$ & 0.000 & 0.159 & 0.302 & $(0.460)$ & 0.193 & $(0.394)$ & 0.000 & 0.180 \\
\hline Science lab & 0.165 & $(0.372)$ & 0.142 & $(0.349)$ & 0.205 & 0.045 & 0.143 & $(0.350)$ & 0.120 & $(0.325)$ & 0.176 & 0.048 \\
\hline Other lab & 0.022 & $(0.147)$ & 0.021 & $(0.145)$ & 0.920 & 0.005 & 0.020 & $(0.141)$ & 0.018 & $(0.133)$ & 0.767 & 0.010 \\
\hline Toilets outside & 0.054 & $(0.227)$ & 0.094 & $(0.291)$ & 0.006 & -0.108 & 0.0443 & $(0.206)$ & 0.070 & $(0.254)$ & 0.045 & -0.079 \\
\hline Toilets inside & 0.980 & $(0.141)$ & 0.967 & $(0.178)$ & 0.150 & 0.057 & 0.992 & $(0.089)$ & 0.981 & $(0.136)$ & 0.101 & 0.068 \\
\hline Freezer & 0.899 & $(0.301)$ & 0.920 & $(0.271)$ & 0.144 & -0.052 & 0.907 & $(0.290)$ & 0.914 & $(0.280)$ & 0.633 & -0.017 \\
\hline Filtered water & 0.845 & $(0.362)$ & 0.825 & $(0.380)$ & 0.299 & 0.038 & 0.881 & $(0.324)$ & 0.858 & $(0.350)$ & 0.183 & 0.048 \\
\hline
\end{tabular}


Table A1 cont.

\begin{tabular}{|c|c|c|c|c|c|c|c|c|c|c|c|c|}
\hline ideo cassettes & 1.757 & $(1.000)$ & 1.763 & $(1.190)$ & 0.911 & 0.000 & 1.501 & $(0.936)$ & 1.551 & (1.368) & 0 & 030 \\
\hline TV sets & 2.038 & $(1.066)$ & 2.025 & $(1.324)$ & 0.541 & 0.024 & 2.107 & (1.021) & 2.108 & (1.353) & 0.980 & -0.001 \\
\hline Projectors & 0.851 & $(0.544)$ & 0.858 & 5) & .815 & -0.009 & 0.867 & $(0.545)$ & 0.876 & 0) & 0.741 & 0.012 \\
\hline Printers & 1.790 & $(2.200)$ & 1.517 & $(2.040)$ & .002 & 0.110 & 2.370 & (2.295) & 1.948 & 1.961) & .000 & 0.140 \\
\hline entium computers & 2.757 & $(4.866)$ & 1.919 & 5) & 00 & 51 & 3.050 & 053) & 2.239 & 35) & 001 & 0.121 \\
\hline 386/486 computers & 0.656 & $(2.486)$ & 0.428 & $(1.4$ & 4 & 0.079 & 1.032 & (3.109) & 0.737 & 9) & 22 & 0.077 \\
\hline Perm. class rooms & 10.069 & (4.8 & 10.060 & & & 35 & 10.651 & 39) & 10.533 & & & 0.017 \\
\hline rov. class rooms & 0.193 & $(0.581)$ & 0.150 & 56) & 092 & 0.058 & 0.165 & $(0.459)$ & 0.172 & $(0.516)$ & .794 & -0.010 \\
\hline Class ro & 9.487 & $(5.188)$ & 9.205 & $(4.195)$ & .223 & 0.042 & 10.010 & $(5.255)$ & 9.760 & 8) & 282 & 0.037 \\
\hline Total s & 49.535 & $(30.3$ & 46.612 & $(25$ & 37 & 0.073 & 51.553 & (31 & 48.281 & 49) & 0.021 & 0.080 \\
\hline Teachers & 32.177 & $(20.045)$ & 30.243 & $(16$ & 35 & 0.074 & 32.441 & $(20.651)$ & 30.207 & 30) & 0.014 & 0.085 \\
\hline Min inc. pro & 0.598 & $(0.491)$ & 0.545 & & & 76 & 0.970 & 1) & 0.967 & & 78 & 012 \\
\hline TV e & 0.732 & $(0$. & 0.751 & & & -0.031 & 0.495 & & 0.564 & & 08 & -0.098 \\
\hline education TV & 0.237 & $(0.4$ & 0.304 & & 0.004 & -0.107 & 0.117 & $(0.321)$ & 0.150 & 58) & 0.062 & -0.069 \\
\hline PROINFO & 0.199 & $(0.400)$ & 0.126 & 2) & .000 & 0.140 & 0.171 & $(0.377)$ & 0.124 & 30) & 0.009 & 0.094 \\
\hline tate & 0.314 & $(0.465)$ & 0.206 & & 0.000 & 0.175 & 0.247 & $(0.432)$ & 0.225 & & 0.309 & 0.037 \\
\hline Iun & 0.091 & & 0.102 & & & -0.026 & 0.175 & & 0.170 & & 0.787 & 0.009 \\
\hline School transport & 0.527 & $(0.500)$ & 0.487 & $(0.500)$ & 0.118 & 0.057 & 0.722 & $(0.448)$ & 0.668 & $(0.471)$ & 0.025 & 0.083 \\
\hline Initic & 72.630 & $(52.326)$ & 69.245 & $(50.132)$ & 0.197 & 0.047 & 38.276 & $(30.966)$ & 41.202 & (32.187) & 0.077 & -0.066 \\
\hline grade & 2.537 & $(1.640)$ & 2.359 & $(1.542)$ & 0.030 & 0.079 & 1.682 & $(1.259)$ & 1.766 & $(1.308)$ & 0.215 & -0.046 \\
\hline Classes in $2^{\text {nd }}$ grade & 2.410 & $(1.420)$ & 2.425 & (1.581) & 0.854 & -0.007 & 1.793 & (1.295) & 1.963 & (1.324) & 0.013 & -0.092 \\
\hline in $3^{\text {rd }}$ grade & 2.348 & $(1.428)$ & 2.470 & $(1.567)$ & 0.125 & -0.058 & 2.163 & $(1.449)$ & 2.123 & $(1.420)$ & 0.587 & 0.020 \\
\hline Classes in $4^{\text {th }}$ grade & 2.334 & $(1.460)$ & 2.469 & $(1.571)$ & 0.080 & -0.063 & 2.082 & $(1.289)$ & 2.076 & (1.314) & 0.919 & 0.003 \\
\hline
\end{tabular}

Notes: The binary variables of school characteristics and programme participation are coded 0 for not present (no participation) and 1 for present (participation). All data is from the Brazilian school census 2003 and 2006. The p-value is reported from a test on the equality of the mean between the treatment and control groups (independent samples). As the sample size is sufficiently large the result for using a classical t-test or taking into account the binary values and the underlying binomial distribution deliver very similar results. As the group size and with it the variances between the groups differ, approximate $t$ using individual sample variances instead of the pooled variance and Welch's approximation of the degrees of freedom have been used.

The normalized difference is computed as norm - diff $=\frac{\bar{x}_{0}-\bar{x}_{1}}{\sqrt{s_{X, 0}^{2}+s_{X, 1}^{2}}}$, where $\mathrm{S}^{2}$ denotes the sample variance of $\mathrm{X}_{\mathrm{i}}$. 
TABLE A1: MEAN CHARACTERISTICS OF TREATMENT AND CONTROL GROUPS IN 2003 AND 2006 CHART B: INDIVIDUAL AND FAMILY CHARACTERISTICS AT SCHOOL LEVEL

\begin{tabular}{|c|c|c|c|c|c|c|c|c|c|c|c|c|}
\hline & \multicolumn{5}{|c|}{2003} & \multicolumn{7}{|c|}{2006} \\
\hline & \multicolumn{2}{|c|}{ Control } & \multicolumn{2}{|c|}{ Treatment } & & \multicolumn{3}{|c|}{ Control } & \multicolumn{2}{|c|}{ Treatment } & \multirow[b]{2}{*}{ P-value } & \multirow[b]{2}{*}{$\begin{array}{c}\text { Norm- } \\
\text { diff }\end{array}$} \\
\hline & Mean & SD & Mean & SD & P-value & $\begin{array}{c}\text { Norm- } \\
\text { diff }\end{array}$ & Mean & $\mathrm{SD}$ & Mean & SD & & \\
\hline Male & 0.492 & $(0.500)$ & 0.495 & $(0.500)$ & 0.414 & -0.004 & 0.490 & $(0.500)$ & 0.498 & $(0.500)$ & 0.028 & -0.011 \\
\hline Age (in months) & 135.43 & $(14.53)$ & 132.01 & $(12.72)$ & 0.000 & 0.177 & 134.53 & (13.73) & 132.22 & $(12.46)$ & 0.000 & 0.125 \\
\hline$\%$ white students & 0.302 & $(0.459)$ & 0.333 & $(0.471)$ & 0.000 & -0.047 & 0.316 & $(0.465)$ & 0.318 & $(0.466)$ & 0.479 & -0.003 \\
\hline$\%$ mixed students & 0.340 & $(0.474)$ & 0.354 & $(0.478)$ & 0.000 & -0.021 & 0.420 & $(0.494)$ & 0.428 & $(0.495)$ & 0.021 & -0.011 \\
\hline$\%$ black students & 0.118 & $(0.323)$ & 0.121 & $(0.326)$ & 0.125 & -0.007 & 0.155 & $(0.362)$ & 0.146 & $(0.363)$ & 0.000 & 0.018 \\
\hline$\%$ Asian students & 0.034 & $(0.181)$ & 0.034 & $(0.181)$ & 0.935 & 0.000 & 0.045 & $(0.206)$ & 0.043 & $(0.203)$ & 0.250 & 0.007 \\
\hline$\%$ indig. students & 0.042 & $(0.200)$ & 0.043 & $(0.203)$ & 0.324 & -0.004 & 0.046 & $(0.210)$ & 0.046 & $(0.209)$ & 0.001 & 0.000 \\
\hline Bathroom & 1.267 & $(0.560)$ & 1.270 & $(1.291)$ & 0.000 & -0.002 & 1.263 & $(0.583)$ & 1.276 & $(0.585)$ & 0.001 & -0.016 \\
\hline TV & 1.323 & $(0.792)$ & 1.321 & $(0.773)$ & 0.762 & 0.002 & 1.495 & $(0.788)$ & 1.487 & $(0.775)$ & 0.171 & 0.007 \\
\hline Video & 0.370 & $(0.483)$ & 0.374 & $(0.484)$ & 0.134 & -0.006 & 0.606 & $(0.689)$ & 0.605 & $(0.687)$ & 0.816 & 0.001 \\
\hline Radio & 1.468 & $(0.796)$ & 1.440 & $(0.790)$ & 0.000 & 0.025 & 1.360 & $(0.752)$ & 1.341 & $(0.738)$ & 0.000 & 0.019 \\
\hline Fridge & 0.954 & $(0.468)$ & 0.978 & $(0.468)$ & 0.000 & -0.036 & 0.995 & $(0.493)$ & 1.002 & $(0.466)$ & 0.054 & -0.010 \\
\hline Freezer & 1.945 & $(0.228)$ & 1.940 & $(0.237)$ & 0.003 & 0.015 & 1.937 & $(0.242)$ & 1.932 & $(0.252)$ & 0.002 & 0.014 \\
\hline Clothes washer & 0.746 & $(0.435)$ & 0.781 & $(0.414)$ & 0.000 & -0.058 & 0.924 & $(0.601)$ & 0.944 & $(0.583)$ & 0.000 & -0.024 \\
\hline Car & 0.621 & $(0.855)$ & 0.660 & $(0.862)$ & 0.000 & -0.032 & 0.641 & $(0.814)$ & 0.672 & $(0.810)$ & 0.000 & -0.027 \\
\hline Computer & 0.170 & $(0.376)$ & 0.176 & $(0.381)$ & 0.022 & -0.011 & 0.254 & $(0.435)$ & 0.258 & $(0.437)$ & 0.229 & -0.006 \\
\hline Books & 21.867 & $(27.328)$ & 22.070 & $(27.612)$ & 0.311 & -0.005 & 20.870 & $(27.850)$ & 20.471 & $(27.664)$ & 0.037 & 0.010 \\
\hline Education (father) & 6.318 & $(19.122)$ & 6.577 & $(19.822)$ & 0.000 & -0.009 & & & & & & \\
\hline Education ( mother) & 6.487 & $(17.682)$ & 6.651 & $(18.365)$ & 0.000 & -0.006 & & & & & & \\
\hline Literate (father) & 0.877 & $(0.108)$ & 0.887 & $(0.100)$ & 0.000 & -0.068 & & & & & & \\
\hline Literate (mother) & 0.905 & $(0.086)$ & 0.910 & $(0.082)$ & 0.029 & -0.038 & & & & & & \\
\hline \multicolumn{13}{|c|}{$\begin{array}{l}\text { Notes: All data is taken from the socio-economic questionnaire of PROEB } 2003 \text { and } 2006 \text {. Information on educational background and literacy of parents is only available } \\
\text { in the } 2003 \text { questionnaire. The p-value is reported from a test on the equality of the mean between the treatment and control groups (independent samples). As the sample } \\
\text { size is sufficiently large the result for using a classical t-test or taking into account the binary values and the underlying binomial distribution deliver very similar results. } \\
\text { As the group size and with it the variances between the groups differ, approximate t using individual sample variances instead of the pooled variance and Welch's } \\
\text { approximation of the degrees of freedom have been used. }\end{array}$} \\
\hline
\end{tabular}


TABLE A2: MEAN PRE-INTERVENTION SCHOOL CHARACTERISTICS IN 1997

\begin{tabular}{lcccccc}
\hline \hline 1997 & \multicolumn{7}{c}{ Control } & \multicolumn{7}{c}{ Treatment } \\
\hline $\mathrm{n}=1,993$ & Mean & SD & Mean & SD & P-value & Norm-diff \\
\hline${\text { Repetition rate } 1^{\text {st }} \text { grade }}^{\text {nd }}$ grade & 0.084 & $(0.108)$ & 0.084 & $(0.106)$ & 0.975 & -0.001 \\
Repetition rate ${ }^{\text {nd }}$ & 0.161 & $(0.208)$ & 0.171 & $(0.200)$ & 0.371 & -0.034 \\
Repetition rate $3^{\text {rd }}$ grade & 0.051 & $(0.053)$ & 0.049 & $(0.143)$ & 0.632 & -0.014 \\
Repetition rate $4{ }^{\text {th }}$ grade & 0.064 & $(0.072)$ & 0.059 & $(0.093)$ & 0.209 & -0.044 \\
\hline Class size $($ grades 1-4) & 32.249 & $(5.871)$ & 31.127 & $(6.480)$ & 0.000 & 0.128 \\
Student-teacher ratio (grades 1-4) & 20.480 & $(3.878)$ & 20.129 & $(4.124)$ & 0.244 & 0.062 \\
\hline
\end{tabular}

Notes: All data is from the Brazilian school census 1997. The p-value is reported from a test on the equality of the mean between the treatment and control groups (independent samples). As the sample size is sufficiently large the result for using a classical t-test or alternatively taking into account the binary values and the underlying binomial distribution deliver very similar results. As the group size and with it the variances between the groups differ, approximate $t$ using individual sample variances instead of the pooled variance and Welch's approximation of the degrees of freedom have been used.

The normalized difference is computed as $m-\operatorname{diff}=\frac{\overline{X_{0}}-\overline{X_{1}}}{\sqrt{S_{X, 0}^{2}+S_{X, 1}^{2}}}$, where $S^{2}$ denotes the sample variance of $\mathrm{X}_{\mathrm{i}}$.

TABLE A3: RESPONSES OF STUDENTS, PARENTS AND TEACHERS

\begin{tabular}{lcccc}
\hline \hline Dependent variable: & & & \\
\hline & $\begin{array}{c}\text { Students doing } \\
\text { homework } \\
(1)\end{array}$ & $\begin{array}{c}\text { Parents help } \\
\text { with homework }\end{array}$ & $\begin{array}{c}\text { Teacher assigns } \\
\text { homework } \\
(2)\end{array}$ & $\begin{array}{c}\text { Teacher corrects } \\
\text { homework } \\
(3)\end{array}$ \\
\hline & $-0.014 *$ & $0.022^{* * *}$ & -0.002 & -0.002 \\
& $(0.008)$ & $(0.008)$ & $(0.003)$ & $(0.009)$ \\
\hline Observations & 217,253 & 212,647 & 220,087 & 215,809 \\
\hline R-squared & 0.003 & 0.041 & 0.001 & 0.003 \\
\hline
\end{tabular}

Notes: $* * *$ denotes significance at $1 \%, *$ denotes significance at $10 \%$. Robust standard errors, adjusted for clustering within schools are reported in parenthesis. The coefficients report the effect of the introduction of automatic promotion behavioural responses of students, parents and teachers. The effects are estimated by a regression corresponding to equation (1) as $y_{i s t}=\beta_{0}+d_{s}+d_{t}+\gamma_{s t}+\epsilon_{i s t}$. The binary outcome variables were constructed using consistent information from the socio-economic questionnaire of PROEB 2003 and 2006. The dependent variable in column(1) reports change in fraction of students always doing their homework (mean 0.706), in column (2) the change in fraction of students always receiving help from their parents with their homework (mean 0.652), in column (3) the change in fraction of teachers assigning homework (mean 0.981), and in column (4) the change in fraction of teachers always correcting homework of their students (mean 0.767). 
TABLE A4: SENSITIVITY OF ESTIMATES TO INDIVIDUAL AND

PEER AGE CONTROLS FOR DIFFERENT AGE RANGES

\begin{tabular}{|c|c|c|c|c|c|c|c|c|}
\hline \multicolumn{9}{|c|}{ Dependent variable: PROEB test scores } \\
\hline \multicolumn{9}{|c|}{ Chart $\mathrm{A}$ - all students } \\
\hline & Peer cc & ntrols & & $\mathrm{r}$ and indi & idual cont & & Individu & controls \\
\hline & $\begin{array}{c}\text { excl. } \\
\text { peer age }\end{array}$ & $\begin{array}{c}\text { incl. } \\
\text { peer age }\end{array}$ & $\begin{array}{c}\text { excl. } \\
\text { ind. and } \\
\text { peer age }\end{array}$ & $\begin{array}{l}\text { incl. ind. } \\
\text { age, } \\
\text { excl. } \\
\text { peer age }\end{array}$ & $\begin{array}{c}\text { incl. } \\
\text { peer } \\
\text { age, } \\
\text { excl. } \\
\text { ind. age }\end{array}$ & $\begin{array}{c}\text { incl. } \\
\text { peer and } \\
\text { ind. age }\end{array}$ & $\begin{array}{l}\text { excl. ind. } \\
\text { age }\end{array}$ & $\begin{array}{l}\text { incl. ind. } \\
\text { age }\end{array}$ \\
\hline & $(1)$ & $(2)$ & $(3)$ & $(4)$ & $(5)$ & $(6)$ & $(7)$ & $(8)$ \\
\hline $\begin{array}{c}\text { Treatment } \\
\text { effect }\end{array}$ & $\begin{array}{c}-5.65 * * * \\
(1.98)\end{array}$ & $\begin{array}{c}-5.67 * * * \\
(1.98)\end{array}$ & $\begin{array}{c}-6.02 * * * \\
(1.98)\end{array}$ & $\begin{array}{c}-6.47 * * * \\
(2.04)\end{array}$ & $\begin{array}{c}-5.78 * * * \\
(1.99)\end{array}$ & $\begin{array}{c}-6.24 * * * \\
(2.04)\end{array}$ & $\begin{array}{c}-6.76^{* * *} \\
(1.96)\end{array}$ & $\begin{array}{c}-6.87 * * * \\
(2.08)\end{array}$ \\
\hline R-squared & 0.01 & 0.01 & 0.12 & 0.17 & 0.12 & 0.17 & 0.12 & 0.16 \\
\hline
\end{tabular}

Chart B - students in target age range for $4^{\text {th }}$ grade

\begin{tabular}{|c|c|c|c|c|c|c|c|c|}
\hline & \multicolumn{2}{|c|}{ Peer controls } & \multicolumn{4}{|c|}{ Peer and individual controls } & \multicolumn{2}{|c|}{ Individual controls } \\
\hline & $\begin{array}{c}\text { excl. peer } \\
\text { age }\end{array}$ & $\begin{array}{c}\text { incl. } \\
\text { peer age }\end{array}$ & $\begin{array}{c}\text { excl. } \\
\text { ind. and } \\
\text { peer age }\end{array}$ & $\begin{array}{c}\text { incl. ind. } \\
\text { age, } \\
\text { excl. } \\
\text { peer age }\end{array}$ & $\begin{array}{c}\text { incl. } \\
\text { peer } \\
\text { age, } \\
\text { excl. } \\
\text { ind. age }\end{array}$ & $\begin{array}{l}\text { incl. } \\
\text { peer and } \\
\text { ind. age }\end{array}$ & $\begin{array}{c}\text { excl. ind. } \\
\text { age }\end{array}$ & $\begin{array}{c}\text { incl. ind. } \\
\text { age }\end{array}$ \\
\hline & (1) & (2) & (3) & (4) & (5) & (6) & (7) & (8) \\
\hline $\begin{array}{c}\text { Treatment } \\
\text { effect }\end{array}$ & $\begin{array}{c}-7.47 * * * \\
(2.23)\end{array}$ & $\begin{array}{c}-7.50 * * * \\
(2.23)\end{array}$ & $\begin{array}{c}-7.30 * * * \\
(2.25)\end{array}$ & $\begin{array}{c}-7.46^{* * * *} \\
(2.25)\end{array}$ & $\begin{array}{c}-7.11 * * * \\
(2.25)\end{array}$ & $\begin{array}{c}-7.22 * * * \\
(2.25)\end{array}$ & $\begin{array}{c}-7.73 * * * \\
(2.26)\end{array}$ & $\begin{array}{c}-7.96 * * * \\
(2.26)\end{array}$ \\
\hline R-squared & 0.01 & 0.01 & 0.13 & 0.13 & 0.13 & 0.13 & 0.12 & 0.12 \\
\hline
\end{tabular}

Notes: *** denotes significance at $1 \%$. All estimates include controls for school characteristics (physical characteristics of the school and the class rooms, teaching material, teacher characteristics, participation in educational programmes etc.) The specifications (1) include additionally controls for peer socio-economic characteristics, specifications (2) control for per and individual characteristics, specifications (3) control for individual characteristics. The row below specifies further controls for individual and peer age in the estimation.

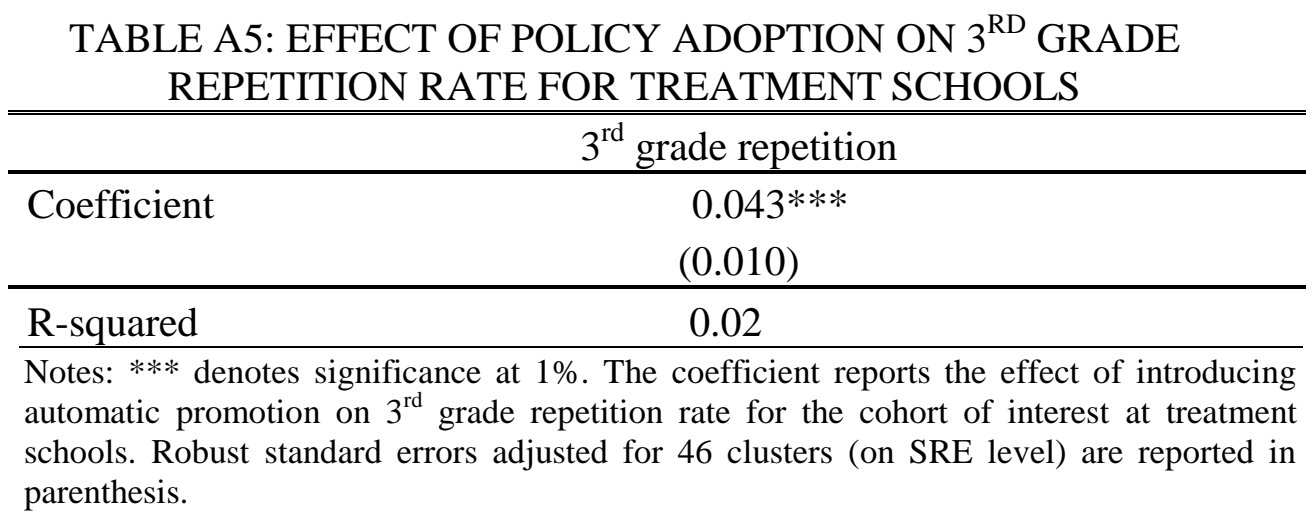


TABLE A6: LINEAR PROBABILITY MODEL OF ASSIGNMENT TO TREATMENT

\begin{tabular}{|c|c|c|c|c|c|}
\hline School provides all yea & rs of fundamental education & $0.061 * *$ & (0.030) & $0.067 * *$ & $(0.027)$ \\
\hline School characteristics & rural school & 0.004 & $(0.039)$ & 0.001 & $(0.036)$ \\
\hline & proper school building & 0.070 & $(0.099)$ & 0.100 & $(0.099)$ \\
\hline & church building & $-0.152 * *$ & $(0.070)$ & -0.128 & $(0.076)$ \\
\hline & teacher home & -0.156 & $(0.175)$ & -0.289 & $(0.170)$ \\
\hline & building of other school & 0.013 & $(0.061)$ & -0.016 & $(0.053)$ \\
\hline & farm building & -0.111 & $(0.120)$ & -0.037 & $(0.113)$ \\
\hline & other building & -0.107 & $(0.059)$ & $-0.119 * *$ & $(0.053)$ \\
\hline & state property & -0.271 & $(0.240)$ & -0.130 & $(0.233)$ \\
\hline & municipal property & -0.380 & $(0.233)$ & -0.210 & $(0.229)$ \\
\hline & private property & -0.348 & $(0.237)$ & -0.227 & $(0.227)$ \\
\hline & school property & -0.061 & $(0.070)$ & -0.076 & $(0.059)$ \\
\hline & rented property & 0.034 & $(0.109)$ & 0.045 & $(0.097)$ \\
\hline & shared school & -0.038 & $(0.023)$ & $-0.052 * *$ & $(0.021)$ \\
\hline & principal office & 0.007 & $(0.033)$ & -0.023 & $(0.030)$ \\
\hline & secretarial office & -0.067 & $(0.042)$ & $-0.083 * *$ & $(0.040)$ \\
\hline & school library & -0.008 & $(0.030)$ & 0.016 & $(0.027)$ \\
\hline & reading room & -0.029 & $(0.052)$ & -0.087 & $(0.046)$ \\
\hline & teacher room & -0.004 & $(0.030)$ & -0.001 & $(0.027)$ \\
\hline & video library & -0.031 & $(0.041)$ & -0.050 & $(0.039)$ \\
\hline & TV room & 0.006 & $(0.024)$ & 0.021 & $(0.022)$ \\
\hline & school kitchen & 0.016 & $(0.029)$ & -0.018 & $(0.027)$ \\
\hline & cafeteria & 0.008 & $(0.024)$ & 0.011 & $(0.021)$ \\
\hline & refectory & $-0.045^{* *}$ & $(0.021)$ & -0.023 & $(0.020)$ \\
\hline & stationary & -0.025 & $(0.024)$ & 0.003 & $(0.022)$ \\
\hline & computer laboratory & 0.017 & $(0.042)$ & 0.012 & $(0.039)$ \\
\hline & science laboratory & 0.011 & $(0.031)$ & 0.003 & $(0.029)$ \\
\hline & other laboratory & 0.018 & $(0.061)$ & -0.005 & $(0.053)$ \\
\hline & toilets outside school & $-0.088^{* *}$ & $(0.036)$ & -0.053 & $(0.033)$ \\
\hline & toilets inside school & 0.023 & $(0.055)$ & -0.013 & $(0.052)$ \\
\hline & toilets ready for special needs & 0.108 & $(0.083)$ & 0.144 & $(0.076)$ \\
\hline & school ready for special needs & -0.062 & $(0.071)$ & -0.022 & $(0.062)$ \\
\hline & industrial oven & 0.021 & $(0.089)$ & 0.056 & $(0.088)$ \\
\hline & home oven & -0.022 & $(0.030)$ & -0.009 & $(0.029)$ \\
\hline & wood oven & 0.052 & $(0.048)$ & 0.016 & $(0.037)$ \\
\hline & freezer & -0.052 & $(0.038)$ & -0.056 & $(0.034)$ \\
\hline & filtered water & $0.051 * *$ & $(0.026)$ & -0.007 & $(0.024)$ \\
\hline & internet access & 0.017 & $(0.033)$ & -0.012 & $(0.030)$ \\
\hline & public energy supply & -0.044 & $(0.247)$ & -0.049 & $(0.162)$ \\
\hline & solar energy & $-0.229 * * *$ & $(0.071)$ & -0.100 & $(0.086)$ \\
\hline & using 220 volt & -0.020 & $(0.040)$ & -0.008 & $(0.037)$ \\
\hline & using $110 \& 220$ volt & $-0.063^{* *}$ & $(0.029)$ & -0.010 & $(0.029)$ \\
\hline & public water supply & -0.025 & $(0.089)$ & 0.061 & $(0.077)$ \\
\hline & artesian well & -0.082 & $(0.086)$ & 0.003 & $(0.076)$ \\
\hline
\end{tabular}




\begin{tabular}{|c|c|c|c|c|c|}
\hline & cistern water & -0.003 & $(0.073)$ & -0.021 & $(0.063)$ \\
\hline & no running water & -0.093 & $(0.250)$ & -0.075 & $(0.267)$ \\
\hline & spring water & -0.060 & $(0.105)$ & -0.034 & $(0.093)$ \\
\hline & public sewerage & 0.055 & $(0.303)$ & 0.125 & $(0.240)$ \\
\hline & septic tank & -0.070 & $(0.303)$ & 0.098 & $(0.241)$ \\
\hline & no sewerage & 0.121 & $(0.319)$ & 0.135 & $(0.250)$ \\
\hline Number of & video tapes & -0.012 & $(0.014)$ & -0.010 & $(0.013)$ \\
\hline & TV sets & -0.006 & $(0.012)$ & -0.004 & $(0.012)$ \\
\hline & printers & -0.001 & $(0.009)$ & 0.002 & $(0.008)$ \\
\hline & overhead projectors & $-0.043^{* *}$ & $(0.021)$ & -0.015 & $(0.020)$ \\
\hline & Pentium computers & 0.008 & $(0.004)$ & 0.004 & $(0.004)$ \\
\hline & $386 / 486$ computers & $0.013 * *$ & $(0.006)$ & $0.013 * *$ & $(0.006)$ \\
\hline & permanent class rooms & -0.015 & $(0.009)$ & -0.007 & $(0.008)$ \\
\hline & provisory class rooms & 0.019 & $(0.023)$ & 0.015 & $(0.022)$ \\
\hline & class rooms in school & 0.017 & $(0.010)$ & 0.013 & $(0.009)$ \\
\hline & class rooms away from school & 0.030 & $(0.015)$ & 0.023 & $(0.013)$ \\
\hline School size proxies & student enrolment 1 st year & -0.000 & $(0.000)$ & 0.000 & $(0.000)$ \\
\hline & total number of staff & 0.000 & $(0.003)$ & 0.002 & $(0.003)$ \\
\hline & total number of teachers & 0.001 & $(0.004)$ & -0.001 & $(0.004)$ \\
\hline & number of teachers in classes $1-4$ & -0.003 & $(0.002)$ & -0.003 & $(0.002)$ \\
\hline School programme & Minimum Income Programme & 0.012 & $(0.020)$ & 0.004 & $(0.022)$ \\
\hline participation & TV escola & -0.007 & $(0.024)$ & 0.012 & $(0.023)$ \\
\hline & Education TV & $-0.040^{*}$ & $(0.022)$ & -0.013 & $(0.021)$ \\
\hline & Parameters in Action & -0.045 & $(0.028)$ & -0.025 & $(0.027)$ \\
\hline & FNDE & 0.005 & $(0.025)$ & -0.025 & $(0.025)$ \\
\hline & Ouvebem & $-0.061 * *$ & $(0.028)$ & -0.025 & $(0.026)$ \\
\hline & Reabvis & -0.025 & $(0.027)$ & -0.007 & $(0.025)$ \\
\hline & School Transport Programme & $0.074 * * *$ & $(0.027)$ & 0.021 & $(0.027)$ \\
\hline & National Library Programme & -0.025 & $(0.021)$ & -0.006 & $(0.019)$ \\
\hline & State computer programme & 0.038 & $(0.062)$ & 0.043 & $(0.059)$ \\
\hline & Municipal computer programme & 0.213 & $(0.179)$ & 0.153 & $(0.170)$ \\
\hline & Proinfo & 0.023 & $(0.039)$ & 0.058 & $(0.036)$ \\
\hline & other state programme & $0.104 * * *$ & $(0.025)$ & 0.008 & $(0.024)$ \\
\hline & other municipal programme & -0.039 & $(0.032)$ & $-0.068 * *$ & $(0.031)$ \\
\hline & Free School Lunch & 0.047 & $(0.170)$ & 0.007 & $(0.181)$ \\
\hline & Free Public School Transport & -0.035 & $(0.024)$ & 0.007 & $(0.022)$ \\
\hline & Constant & 0.634 & $(0.504)$ & 0.807 & $(0.440)$ \\
\hline Observations & & & 1,99 & & \\
\hline SRE dummies & & No & & Yes & \\
\hline R-squared & & 0.09 & & 0.28 & \\
\hline
\end{tabular}

Notes: * significant at 10\%; ** significant at 5\%; *** significant at $1 \%$, standard errors are in parenthesis. The data is taken from the 2003 school census. Specification (2) includes regional school administration dummies (SRE). Most of the physical characteristics describing the schools are indicator variables on the presence at school. Similarly, indicator variables inform about participation in education programmes. The programme Parameters in Action is a federal programme for the professional development of teachers; FNDE denotes a maintenance and development programme for education by the National Fund for the Development of Education, Ouvebem is a national campaign for the importance of the sense of hearing, Reabvis is a national campaign on visual rehabilitation, $P R O I N F O$ is a federal computer literacy programme. The coefficients reported are from two specifications of a linear model of the effect of school characteristics on the 
probability for treatment. The dependent variable is an indicator that equals zero for being in treatment group and equals 1 for being in the control group. In specification (1) only very few coefficients are significant at the $1 \%$ and $5 \%$ level of significance, of which some disappear when including regional dummies (specification (2). None of the coefficients of the linear model produces values outside the unit-interval and a logit specification delivers very similar results to the linear specification diminishing doubts on the suitability of the linear specification (not reported). 